\title{
Evaluation of Operational Models of Agonism and Allosterism at Receptors with Multiple Orthosteric Binding Sites ${ }^{\circledR}$
}

\author{
Karen J. Gregory, Jesús Giraldo, Jiayin Diao, Arthur Christopoulos, and Katie Leach
}

Drug Discovery Biology and Department of Pharmacology, Monash Institute of Pharmaceutical Sciences, Monash University, Parkville, Melbourne, Australia (K.J.G., J.D., A.C., K.L.); Laboratory of Molecular Neuropharmacology and Bioinformatics, Institut de Neurociències and Unitat de Bioestadística, Facultat de Medicina, Universitat Autònoma de Barcelona, Barcelona, Spain (J.G.); Instituto de Salud Carlos III, Centro de Investigación Biomédica en Red de Salud Mental, Bellaterra, Spain (J.G.); and Unitat de Neurociència Traslacional, Parc Taulí Hospital Universitari, Institut d'Investigació i Innovació Parc Taulí and Institut de Neurociències, Universitat Autònoma de Barcelona, Bellaterra, Spain (J.G.)

Received August 12, 2019; accepted November 4, 2019

\section{ABSTRACT}

Current operational models of agonism and allosterism quantify ligand actions at receptors where agonist concentrationresponse relationships are nonhyperbolic by introduction of a transducer slope that relates receptor occupancy to response. However, for some receptors nonhyperbolic concentrationresponse relationships arise from multiple endogenous agonist molecules binding to a receptor in a cooperative manner. Thus, we developed operational models of agonism in systems with cooperative agonist binding and evaluated the models by simulating data describing agonist effects. The models were validated by analyzing experimental data demonstrating the effects of agonists and allosteric modulators at receptors where agonist binding follows hyperbolic $\left(\mathrm{M}_{4}\right.$ muscarinic acetylcholine receptors) or nonhyperbolic relationships (metabotropic glutamate receptor 5 and calcium-sensing receptor). For hyperbolic agonist concentration-response relationships, no differences in estimates of ligand affinity, efficacy, or cooperativity were observed when the slope was assigned to either a transducer slope or agonist binding slope. In contrast, for receptors with nonhyperbolic agonist concentration-response relationships, estimates of ligand affinity, efficacy, or cooperativity varied depending on the assignment of the slope. The extent of this variation depended on the magnitude of the slope value and agonist efficacy, and for allosteric modulators on the magnitude of cooperativity. The modified operational models described herein are well suited to analyzing agonist and modulator interactions at receptors that bind multiple orthosteric agonists in a cooperative manner. Accounting for cooperative agonist binding is essential to accurately quantify agonist and drug actions.

\section{SIGNIFICANCE STATEMENT}

Some orthosteric agonists bind to multiple sites on a receptor, but current analytical methods to characterize such interactions are limited. Herein, we develop and validate operational models of agonism and allosterism for receptors with multiple orthosteric binding sites, and demonstrate that such models are essential to accurately quantify agonist and drug actions. These findings have important implications for the discovery and development of drugs targeting receptors such as the calcium-sensing receptor, which binds at least five calcium ions.
This work was supported by the National Health and Medical Research Council of Australia [Project Grants APP1085143 (to K.L.), APP1138891 (to K.L. and K.J.G.), APP1084775 (to K.J.G.), and APP1127322 (to K.J.G.); Program Grant APP1055134 (to A.C.); and Senior Principal Research Fellowship APP1102950 (to A.C.)]; the Australian Research Council [Discovery Grant DP170104228 (to K.L. and K.J.G.), and Future Fellowships FT160100075 (to K.L.) and FT170100392 (to K.J.G.)]; and the Ministerio de Ciencia, Innovación y Universidades of Spain [Project Grant SAF2017-87199-R (to J.G.)]

https://doi.org/10.1124/mol.119.118091.

S This article has supplemental material available at molpharm. aspetjournals.org.

\section{Introduction}

The past 30 years have seen major advances in quantifying the relationship between receptor occupancy and response, with the operational model of agonism (Black and Leff, 1983) representing one of the most common analytical approaches. The operational model of agonism describes agonist effects based on agonist affinity [equilibrium dissociation constant of the orthosteric agonist $\left.\left(K_{\mathrm{A}}\right)\right]$ and observed efficacy in a given test system. The latter is defined by a transducer ratio $(\tau)$,

ABBREVIATIONS: AC265347, 1-(1,3-benzothiazol-2-yl)-1-(2,4-dimethylphenyl)ethanol; $\mathrm{ACh}$, acetylcholine; $\mathrm{Ca}_{\mathrm{i}}^{2+}$, intracellular calcium; $\mathrm{Ca}_{\circ}^{2+}$, extracellular calcium; calcimimetic B, R-1-(6-methoxy-4'-(trifluoromethyl)-3-biphenylyl)-N-(R)- 1-phenylethyl)ethanamine; CaSR, calcium-sensing receptor; DMEM, Dulbecco's modified Eagle's medium; DPFE, 1-(4-(2,4-difluorophenyl)piperazin-1-yl)-2-((4-fluorobenzyl)oxy)ethanone; $E_{\mathrm{m}}$, maximal system response; $E_{\max }$, maximum effect; GPCR, G protein-coupled receptor; HEK, human embryonic kidney; $K_{\mathrm{A}}$, equilibrium dissociation constant of the orthosteric agonist; $K_{\mathrm{B}}$, equilibrium dissociation constant of the allosteric ligand; LY2033298, 3-amino-5-chloro-6-methoxy-4methyl-thieno[2,3-b]pyridine-2-carboxylic acid cyclopropylamide; M-5MPEP, 2-[2-(3-methoxyphenyl)ethynyl]-5-methylpyridine; mAChR, muscarinic acetylcholine receptor; mGlu, metabotropic glutamate receptor; MPEP, 2-methyl-6-(2-phenylethynyl)pyridine; NAM, negative allosteric modulator; $n_{\mathrm{B}}$, binding slope linking agonist concentration to receptor occupancy; $n_{\mathrm{H}}$, Hill slope; $n_{\mathrm{T}}$, transducer slope linking agonist concentration to response; NPS2143, 2-chloro-6-[(2R)-2-hydroxy-3-[(2-methyl-1-naphthalen-2-ylpropan-2-yl)amino]propoxy]benzonitrile; PAM, positive allosteric modulator; WT, wild type; VE-29, 2-chloro-6-[(2R)-2-hydroxy-3-[(2-methyl-1-naphthalen-2-ylpropan-2-yl)amino]propoxy]benzonitrile. 
which is a function of both tissue- and agonist-specific components; it is the ratio of the total receptor number and a transducer parameter that defines the avidity with which a given agonist-occupied receptor complex promotes the final observed pharmacological effect. As such, the operational model of agonism is a useful tool for quantifying agonism in a comparable manner across different test systems (Black and Leff, 1983), and has subsequently been extended or modified to also quantify effects of allosteric modulators and biased agonists (Leach et al., 2007, 2010; Kenakin, 2012).

The operational model of agonism has been most commonly applied to characterize the activity of agonists that display both rectangular hyperbolic or nonhyperbolic concentration-response curves, i.e., normally empirically characterized by Hill slopes that are equal to or different from unity, respectively. The key underlying assumption in the majority of instances to date where an agonist concentration-response curve displays a Hill slope significantly different from 1 has been ascribed in the most common form of the operational model to differences in the postreceptor machinery that transduces occupancy to response, i.e., through introduction of a so-called transducer slope $(n)$ (Black et al., 1985). For instance, steep or shallow Hill slopes could arise due to changes in the sensitivity of one or more steps in a receptor's signal transduction mechanism, while the initial agonistreceptor binding event is assumed to be characterized by a simple hyperbolic one-to-one relationship. However, for ion channels and a number of $\mathrm{G}$ protein-coupled receptors (GPCRs), particularly the class C GPCR subfamily, nonhyperbolic concentrationresponse relationships can also arise from cooperative binding of multiple equivalents of the same endogenous agonist molecule prior to any subsequent processing of the stimulus by the cellular transduction machinery. For example, while a number of small molecule calcium-sensing receptor (CaSR) agonists produce responses characterized by Hill slopes close to unity (Cook et al., 2015; Keller et al., 2018), indicating a transducer slope equal to unity, it is also well established that CaSR responses to its endogenous activator, extracellular calcium $\left(\mathrm{Ca}_{\mathrm{o}}^{2+}\right)$, and other divalent cations are characterized by extremely high Hill slopes, ranging from 2 to 4 (Brown, 1983; Davey et al., 2012; Leach et al., 2015). The most parsimonious explanation to account for these disparate observations is that the operational transducer slope linking CaSR agonist occupancy to response can adequately be described by a transducer slope equal to unity, which suggests that the cooperativity observed in response to activators such as $\mathrm{Ca}_{\mathrm{o}}^{2+}$ ions arises at the level of binding, not function. This is also in accord with known pharmacological and structural studies of the CaSR that have identified multiple binding sites for $\mathrm{Ca}_{0}^{2+}$ ions (Geng et al., 2016). As a consequence, the classic operational model of agonism as applied to concentration-response curves of nonunit Hill slopes is suboptimal for such situations.

Herein, we sought to develop and evaluate an operational model of agonism that describes orthosteric agonist binding to multiple sites in a cooperative manner, referred to as the cooperative agonist operational model. The cooperative agonist operational model was superior to the original BlackLeff operational model of agonism in fitting $\mathrm{Ca}_{\mathrm{o}}^{2+}$-CaSR concentration-response data. We also extended this cooperative agonist operational model to incorporate allosteric modulation of the affinity and efficacy of an agonist that binds cooperatively to multiple sites. This operational model of allosterism with cooperative agonist binding was fitted to data describing the actions of CaSR positive allosteric modulators (PAMs) and negative allosteric modulators (NAMs), and revealed that if cooperative agonist binding is not taken into consideration, under- or overestimates of PAM and NAM affinity and cooperativity can occur.

\section{Materials and Methods}

Materials. Dulbecco's modified Eagle's medium (DMEM), Flp-In human embryonic kidney (HEK) T-REx cells, blasticidin S HCl, and FBS were obtained from Invitrogen (Carlsbad, CA), while hygromycin B was obtained from Roche (Mannheim, Germany). Fluo-8 AM was obtained from Abcam (Cambridge, MA).

CaSR-Expressing HEK293 Cell Lines. The generation of DNA and Flp-In HEK T-REx cells stably expressing c-myc-tagged wild-type (WT) CaSR in pcDNA5/frt/TO have been described previously (Davey et al., 2012; Leach et al., 2016). Flp-In HEK T-REx CaSR cells were maintained in DMEM containing 5\% FBS, $200 \mu \mathrm{g} / \mathrm{ml}$ hygromycin B, and $5 \mu \mathrm{g} / \mathrm{ml}$ blasticidin S HCl. To generate a tetracycline-inducible Flp-In HEK cell line stably expressing an N-terminally truncated CaSR, N-terminally truncated CaSR corresponding to amino acids 600-903 with an N-terminal influenza hemagglutinin signal peptide followed by a c-myc epitope and rhodopsin signal peptide in pcDNA3.1+ (Leach et al., 2016) was transferred to pcDNA5/frt/TO using BamHI and NotI restriction sites. Flp-In HEK T-REx cells were seeded into $25 \mathrm{~cm}^{2}$ flasks in DMEM containing $5 \% \mathrm{FBS}$ and allowed to reach $80 \%$ confluency. Cells were transfected with $0.5 \mu \mathrm{g} \mathrm{pcDNA5/frt/}$ TO containing the N-terminally truncated CaSR plus $5 \mu \mathrm{g}$ POG44 with lipofectamine 2000 (1:4 DNA:lipofectamine 2000) according to the manufacturer's instructions. The following day, cells were transferred to a $\mathrm{T} 75 \mathrm{~cm}^{2}$ flask, and 24 hours later DMEM was replaced with DMEM containing 5\% FBS, $200 \mu \mathrm{g} / \mathrm{ml}$ hygromycin, and $5 \mu \mathrm{g} / \mathrm{ml}$ blasticidin S HCl. The selection DMEM was replaced every 3 days until untransfected cells had died ( $\sim 10$ days), and antibiotic-resistant cells were expanded and maintained in DMEM containing 5\% FBS, $200 \mu \mathrm{g} / \mathrm{ml}$ hygromycin, and $5 \mu \mathrm{g} / \mathrm{ml}$ blasticidin S HCl. All cell lines were routinely tested for mycoplasma contamination using the Lonza MycoAlert mycoplasma detection kit.

Determination of WT and N-Terminally Truncated CaSR Cell Surface Expression Using Fluorescence-Activated Cytometry. Flp-In HEK T-REx WT and N-terminally truncated CaSR-expressing cells were seeded at 80,000 cells per well into a 96well plate and expression was induced with $100 \mathrm{ng} / \mathrm{ml}$ tetracycline overnight at $37^{\circ} \mathrm{C}$. The following day, cells were harvested and washed in $1 \mathrm{X}$ PBS with $0.1 \%$ bovine serum albumin and $2 \mathrm{mM}$ EDTA (wash buffer) by centrifugation $\left(350 \mathrm{~g}, 4^{\circ} \mathrm{C}\right.$ for 3 minutes) before resuspension and 30-minute incubation in $100 \mu \mathrm{l}$ blocking buffer (1X PBS, $5 \%$ bovine serum albumin, and $2 \mathrm{mM}$ EDTA) containing $1 \mu \mathrm{g} / \mathrm{ml} \mathrm{AF647-}$ conjugated 9E10 made in-house as previously described (Cook et al., 2015). Cells were washed as previously described and resuspended in wash buffer containing propidium iodide. Live cell fluorescence was measured using a BD FACS Canto analyzer (Becton Dickinson).

Calcium Mobilization Assays. Cells were seeded in clear 96well plates coated with poly-D-lysine $\left(50 \mu \mathrm{g} / \mathrm{ml}^{-1}\right)$ at 80,000 cells per well and incubated overnight in the presence of 0 or $100 \mathrm{ng} / \mathrm{ml}^{-1}$ tetracycline. The following day, cells were washed with assay buffer (150 mM NaCl, $2.6 \mathrm{mM} \mathrm{KCl}, 1.18 \mathrm{mM} \mathrm{MgCl}_{2}, 10 \mathrm{mM}$ D-Glucose, $10 \mathrm{mM}$ HEPES, $0.1 \mathrm{mM} \mathrm{CaCl}_{2}, 0.5 \%$ bovine serum albumin, and $4 \mathrm{mM}$ probenecid at $\mathrm{pH} 7.4)$ and loaded with Fluo-8 AM (1 $\mu \mathrm{M}$ in assay buffer) for 1 hour at $37^{\circ} \mathrm{C}$. Cells were washed with assay buffer prior to the addition of fresh assay buffer.

For all studies, each well was treated with a single agonist concentration. The release of intracellular calcium $\left(\mathrm{Ca}_{\mathrm{i}}^{2+}\right)$ was measured at $37^{\circ} \mathrm{C}$ using FlexStation 1 or 3 (Molecular Devices, Sunnyvale, CA). Fluorescence was detected for 60 seconds at $490 \mathrm{~nm}$ excitation and $520 \mathrm{~nm}$ emission and the peak $\mathrm{Ca}_{\mathrm{i}}^{2+}$ mobilization response (approximately 12 seconds after agonist addition) was used for the subsequent determination of the agonist response. Relative peak 
fluorescence units were normalized to the fluorescence stimulated by $1 \mu \mathrm{M}$ ionomycin to account for differences in cell number and loading efficiency.

Model Derivation and Data Analysis. The derivation of operational models describing the effect of an agonist in the absence or presence of an allosteric modulator at a receptor with multiple agonist binding sites is presented in the Supplemental Appendix. The script input to use the two equations in the GraphPad Prism program is also presented in the Supplemental Appendix.

Data simulations were performed using the original Black-Leff operational model of agonism, referred to hereinafter as the Black-Leff
Data describing the interaction between glutamate and PAMs and NAMs at metabotropic glutamate receptor (mGlu) subtype 5, or between acetylcholine (ACh) and 3-amino-5-chloro-6-methoxy4-methyl-thieno[2,3-b]pyridine-2-carboxylic acid cyclopropylamide (LY2033298) at the $\mathrm{M}_{4}$ muscarinic acetylcholine receptor (mAChR), were fitted to our original operational model of allosterism (eq. 3) or to the new operational model of allosterism with cooperative agonist binding (eq. 4). For simplicity and for the purpose of fitting experimental data, eqs. 3-8 assume a single allosteric modulator binding site; therefore, they do not take into account modulator cooperative binding:

$$
\begin{gathered}
\text { Effect }=\frac{E_{\mathrm{m}}\left\{\tau_{\mathrm{A}}[\mathrm{A}]\left(K_{\mathrm{B}}+\alpha \beta[\mathrm{B}]\right)+\tau_{\mathrm{B}}[\mathrm{B}]\left[K_{\mathrm{A}}\right]\right\}^{n_{\mathrm{T}}}}{\left([\mathrm{A}] K_{\mathrm{B}}+K_{\mathrm{A}} K_{\mathrm{B}}+K_{\mathrm{A}}[\mathrm{B}]+\alpha[\mathrm{A}][\mathrm{B}]\right)^{n_{\mathrm{T}}}+\left\{\tau_{\mathrm{A}}[\mathrm{A}]\left(K_{\mathrm{B}}+\alpha \beta[\mathrm{B}]\right)+\tau_{\mathrm{B}}[\mathrm{B}] K_{\mathrm{A}}\right\}^{n_{\mathrm{T}}}} \\
\text { Effect }=\frac{E_{\mathrm{m}}\left\{\tau_{\mathrm{A}}[\mathrm{A}]^{n_{\mathrm{B}}}\left(K_{\mathrm{B}}+\alpha \beta[\mathrm{B}]\right)+\tau_{\mathrm{B}}[\mathrm{B}]\left[K_{\mathrm{A}}\right]^{n_{\mathrm{B}}}\right\}^{n_{\mathrm{T}}}}{\left([\mathrm{A}]^{n_{\mathrm{B}}} K_{\mathrm{B}}+K_{\mathrm{A}}^{n_{\mathrm{B}}} K_{\mathrm{B}}+K_{\mathrm{A}}^{n_{\mathrm{B}}}[\mathrm{B}]+\alpha[\mathrm{A}]^{n_{\mathrm{B}}}[\mathrm{B}]\right)^{n_{\mathrm{T}}}+\left\{\tau_{\mathrm{A}}[\mathrm{A}]^{n_{\mathrm{B}}}\left(K_{\mathrm{B}}+\alpha \beta[\mathrm{B}]\right)+\tau_{\mathrm{B}}[\mathrm{B}] K_{\mathrm{A}}^{n_{\mathrm{B}}}\right\}^{n_{\mathrm{T}}}}
\end{gathered}
$$

model (eq. 1), or a modified cooperative agonist operational model (eq. 2), where an additional slope [i.e., the binding slope linking agonist concentration to receptor occupancy $\left.\left(n_{\mathrm{B}}\right)\right]$ was incorporated to take into account multiple agonist binding sites, and thus the steepness of the slope describing the agonist concentration-occupancy relationship:

$$
\begin{gathered}
\text { Effect }=\frac{E_{\mathrm{m}} \tau_{\mathrm{A}}^{n_{\mathrm{T}}}[\mathrm{A}]^{n_{\mathrm{T}}}}{\tau_{\mathrm{A}}^{n_{\mathrm{T}}}[\mathrm{A}]^{n_{\mathrm{T}}}+\left([\mathrm{A}]+K_{\mathrm{A}}\right)^{n_{\mathrm{T}}}} \\
\text { Effect }=\frac{E_{\mathrm{m}} \tau_{\mathrm{A}}^{n_{\mathrm{T}}}[\mathrm{A}]^{n_{\mathrm{B}} n_{\mathrm{T}}}}{\tau_{\mathrm{A}}^{n_{\mathrm{T}}}[\mathrm{A}]^{n_{\mathrm{B}} n_{\mathrm{T}}}+\left([\mathrm{A}]^{n_{\mathrm{B}}}+K_{\mathrm{A}}^{n_{\mathrm{B}}}\right)^{n_{\mathrm{T}}}}
\end{gathered}
$$

where $[\mathrm{A}]$ is the agonist concentration, $K_{\mathrm{A}}$ is the agonist equilibrium dissociation constant; $\tau_{\mathrm{A}}$ is an operational measure of agonist efficacy; $E_{\mathrm{m}}$ is the maximal system response; and $n_{\mathrm{T}}$ is the transducer slope linking agonist concentration to response.

For simplicity, the modified cooperative operational model of agonism (eq. 2) makes the following assumptions:

1. The receptor is either empty or fully occupied, and only the fully occupied receptor exerts an effect. The lack of partially occupied receptor molecules could arise if multiple agonist molecules bind simultaneously to the receptor, or if agonist molecules bind sequentially with high positive cooperativity. Thus, once one binding site is occupied, positive cooperativity drives occupancy of all other sites. The latter scenario is most likely; hence, this is why we have called this model the cooperative agonist operational model.

2. The model cannot discern cooperativity between the multiple binding sites, thus $n_{\mathrm{B}}$ may not be the true number of binding sites; therefore, $n_{\mathrm{B}}$ is a binding slope coefficient.

3. The $K_{\mathrm{A}}$ value is a geometric mean of the microscopic dissociation constants for each binding site.

The Eqs. 1 or 2 were fitted to agonist concentration response data in order to quantify agonist affinity and efficacy. When fitting eq. 2 to experimental data, the transducer slope was constrained to unity (see Results for validation of this assumption). where $K_{\mathrm{A}}$ is the equilibrium dissociation constant of the orthosteric agonist, which was fixed in some instances to the affinity determined in radioligand binding assays (Mutel et al., 2000; Leach et al., 2010); $K_{\mathrm{B}}$ is the equilibrium dissociation constant of the allosteric ligand; $\tau_{\mathrm{A}}$ and $\tau_{\mathrm{B}}$ are the operational efficacies of the orthosteric agonist and allosteric ligand, respectively; $\alpha$ and $\beta$ are the allosteric effects on orthosteric agonist affinity and efficacy, respectively (it should be noted that $\beta$ is not a reciprocal efficacy cooperativity factor) (Leach et al., 2007; Giraldo, 2015); and [A] and [B] are the orthosteric agonist and allosteric ligand concentrations, respectively.

To fit the operational model of allosterism to data describing the interaction between $\mathrm{Ca}_{0}^{2+}$ and cinacalcet at the CaSR, the original operational model of allosterism shown by eq. 3 was simplified, because for a full agonist like $\mathrm{Ca}_{\mathrm{o}}^{2+}$ (i.e., one that generates the maximal system response at submaximal receptor occupancies) $K_{\mathrm{A}}$ $>>[A]$. Furthermore, because the CaSR's orthosteric agonist, $\mathrm{Ca}_{0}^{2+}$, was present in the assay buffer, the contaminating agonist was included in the equations used to analyze CaSR PAM (cinacalcet) and NAM (2-chloro-6-[(2R)-2-hydroxy-3-[(2-methyl-1-naphthalen-2ylpropan-2-yl)amino]propoxy]benzonitrile [NPS2143]) data (Keller et al., 2018). Therefore, data describing the interaction between $\mathrm{Ca}^{2+}$ and cinacalcet or NPS2143 at the CaSR were fitted to the original operational model of allosterism with the contaminating agonist (eqs. 5 and 6, respectively) or to an operational model of allosterism with cooperative agonist binding and contaminating agonist (eqs. 7 and 8, respectively):

$$
\mathrm{Effect}=\frac{E_{\mathrm{m}}\left\{[\mathrm{A}+\mathrm{C}]\left(K_{\mathrm{B}}+\alpha \beta[\mathrm{B}]\right)+\tau_{\mathrm{B}}[\mathrm{B}]\left[\mathrm{EC}_{50}\right]\right\}^{n_{\mathrm{T}}}}{\left[\mathrm{EC}_{50}\right]^{n_{\mathrm{T}}}\left(K_{\mathrm{B}}+[\mathrm{B}]\right)^{n_{\mathrm{T}}}+\left\{[\mathrm{A}+\mathrm{C}]\left(K_{\mathrm{B}}+\alpha \beta[\mathrm{B}]\right)+\tau_{\mathrm{B}}[\mathrm{B}]\left[\mathrm{EC}_{50}\right]\right\}^{n_{\mathrm{T}}}}
$$

where $\mathrm{EC}_{50}$ is the agonist concentration that elicits a half-maximal response, in which it should be noted that inclusion of $\left[\mathrm{EC}_{50}\right]$ involves some simplifying assumptions that facilitate data fitting (Aurelio et al., 2009; Giraldo, 2015); [C] is the contaminating agonist concentration; and all other parameters are as described for eq. 3 :

$$
\begin{gathered}
\text { Effect }=\frac{E_{\mathrm{m}}\left\{\tau_{A}[\mathrm{~A}+\mathrm{C}]\left(K_{\mathrm{B}}+\alpha \beta[\mathrm{B}]\right)+\tau_{\mathrm{B}}(\mathrm{B})\left[K_{\mathrm{A}}\right]\right\}^{n_{\mathrm{T}}}}{\left([\mathrm{A}] K_{\mathrm{B}}+K_{\mathrm{A}} K_{\mathrm{B}}+K_{\mathrm{A}}[\mathrm{B}]+\alpha[\mathrm{A}+\mathrm{C}][\mathrm{B}]\right)^{n_{\mathrm{T}}}+\left\{\tau_{\mathrm{A}}[\mathrm{A}+\mathrm{C}]\left(K_{\mathrm{B}}+\alpha \beta[\mathrm{B}]\right)+\tau_{\mathrm{B}}[\mathrm{B}] K_{\mathrm{A}}\right\}^{n_{\mathrm{T}}}} \\
\quad \mathrm{Effect}=\frac{E_{\mathrm{m}}\left\{[\mathrm{A}+\mathrm{C}]^{n_{\mathrm{B}}}\left(K_{\mathrm{B}}+\alpha \beta[\mathrm{B}]\right)+\tau_{\mathrm{B}}[\mathrm{B}]\left[\mathrm{EC}_{50}\right]^{n_{\mathrm{B}}}\right\}^{n_{\mathrm{T}}}}{\left[\mathrm{EC}_{50}\right]^{n_{\mathrm{B}} n_{\mathrm{T}}}\left(K_{\mathrm{B}}+[\mathrm{B}]\right)^{n_{\mathrm{T}}}+\left\{[\mathrm{A}+\mathrm{C}]^{n_{\mathrm{B}}}\left(K_{\mathrm{B}}+\alpha \beta[\mathrm{B}]\right)+\tau_{\mathrm{B}}[\mathrm{B}]\left[\mathrm{EC}_{50}\right]^{n_{\mathrm{B}}}\right\}^{n_{\mathrm{T}}}}
\end{gathered}
$$



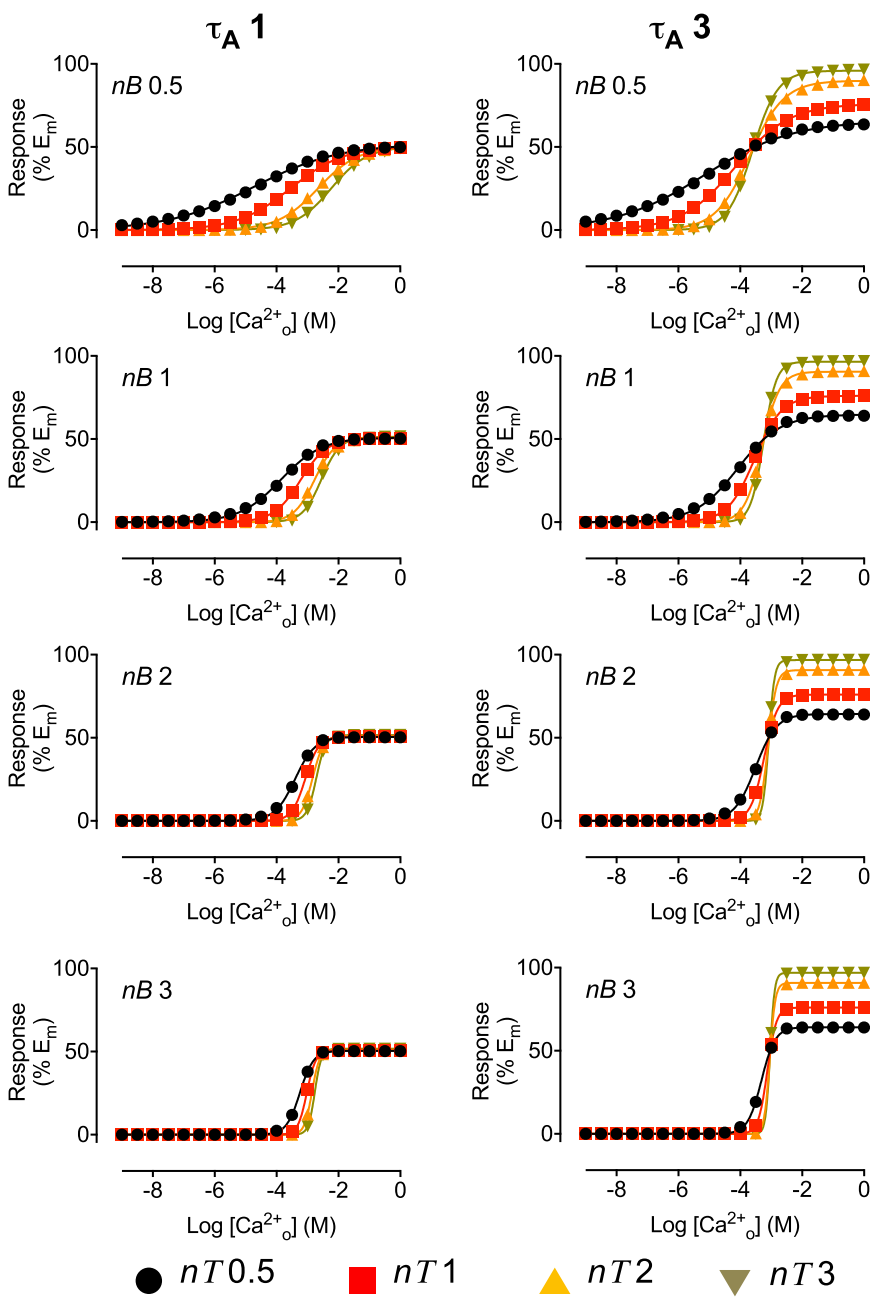

Fig. 1. The $n_{\mathrm{T}}$ and $n_{\mathrm{B}}$ values differentially contribute to agonist concentration-response relationships. Simulations demonstrating the influence of $n_{\mathrm{T}}$ or $n_{\mathrm{B}}$ on concentration-response relationships for agonists with different efficacies $\left(\tau_{\mathrm{A}}\right)$. Data were simulated using the cooperative agonist operational model (eq. 2), where the affinity of the agonist $\left(K_{\mathrm{A}}\right)$ is $1.2 \mathrm{mM}$ and $n_{\mathrm{T}}$ and $n_{\mathrm{B}}$ are between 1 and 3 . Curves through the data are the fits to a four-parameter Hill equation (eq. 9), where the parameters describing the fits are given in Table 1.

where $\mathrm{EC}_{50}, K_{\mathrm{B}}, \tau_{\mathrm{B}}, \alpha, \beta,[\mathrm{A}],[\mathrm{B}],[\mathrm{C}]$, and $E_{\mathrm{m}}$ are as described for eq. 5 : estimated as logarithms (Christopoulos, 1998). An extra sum of squares $F$ test was used to determine whether data were fitted best when the Hill slope, binding slope, or transducer slope $\left(n_{\mathrm{H}}, n_{\mathrm{B}}\right.$, or $n_{\mathrm{T}}$, respectively) were significantly different from unity, where $P<0.05$ was considered significant.

\section{Results}

The Contribution of Slope Factors to Agonist Concentration-Response Relationships. We first evaluated the contribution of the agonist binding slope $\left(n_{\mathrm{B}}\right)$ or transducer slope $\left(n_{\mathrm{T}}\right)$ to the concentration-response curve of two agonists with different efficacies by simulating variations in $n_{\mathrm{B}}$ or $n_{\mathrm{T}}$ using the cooperative agonist operational model (eq. 2). We specifically wanted to evaluate a system with cooperative agonist binding; therefore, we based our simulations on $\mathrm{Ca}_{\mathrm{o}}^{2+}$ activation of the CaSR. The $\mathrm{Ca}_{\mathrm{o}}^{2+}$ concentrationresponse relationship for the CaSR's best characterized physiologic role, inhibition of parathyroid hormone secretion, occurs over a $\mathrm{Ca}_{0}^{2+}$ concentration range of $0.8-1.5 \mathrm{mM}$ with an $\mathrm{EC}_{50}$ value of $\sim 1.2 \mathrm{mM}$ (Brown, 1983). Thus, for these simulations, the affinity of the agonist $\left(K_{\mathrm{A}}\right)$ was assumed to be $1.2 \mathrm{mM}$ and $n_{\mathrm{B}}$ or $n_{\mathrm{T}}$ were assumed to be between 1 and 3 . Simulated data were subsequently fitted to a Hill equation (eq. 9). Unsurprisingly, increasing $n_{\mathrm{B}}$ or $n_{\mathrm{T}}$ increases the Hill slope of the agonist concentration-response curve (Fig. 1; Table 1). Furthermore, increasing $n_{\mathrm{T}}$ decreases agonist potency. Interestingly, the effect of $n_{\mathrm{B}}$ on agonist potency depends on the magnitude of $n_{\mathrm{T}}$ and $\tau_{\mathrm{A}}$. For instance, increasing $n_{\mathrm{B}}$ decreases agonist potency for higher efficacy agonists $\left(\tau_{\mathrm{A}} 3\right)$. However, for lower efficacy agonists $\left(\tau_{\mathrm{A}} 1\right)$, increasing $n_{\mathrm{B}}$ decreases agonist potency when $n_{\mathrm{T}} \leq 1$, but increases agonist potency when $n_{\mathrm{T}} \geq 2$.

We next sought to directly compare the influence of the binding or transducer slope by simulating concentrationresponse curves for agonists with varying efficacies using the Black-Leff operational model (eq. 1, which contains a transducer slope, $n_{\mathrm{T}}$ ) and the cooperative agonist operational model (eq. 2, which contains transducer and binding slopes, $n_{\mathrm{T}}$ and $n_{\mathrm{B}}$, respectively). As can be seen in Fig. 2 and Table 2 , when $n_{\mathrm{T}}$ or $n_{\mathrm{B}}$ are equal to 1 , variations in $\tau_{\mathrm{A}}$ have an identical effect on empirical agonist concentration-response parameters (potency, Hill slope, or $E_{\max }$ ) regardless of the model. In contrast, when $n_{\mathrm{T}}$ or $n_{\mathrm{B}}$ are greater than 1 , variations in $\tau_{\mathrm{A}}$ result in major differences in the agonist

$$
\text { Effect }=\frac{E_{\mathrm{m}}\left\{\tau_{\mathrm{A}}[\mathrm{A}+\mathrm{C}]^{n_{\mathrm{B}}}\left(K_{\mathrm{B}}+\alpha \beta[\mathrm{B}]\right)+\tau_{\mathrm{B}}[\mathrm{B}]\left[K_{\mathrm{A}}\right]^{n_{\mathrm{B}}}\right\}^{n_{\mathrm{T}}}}{\left([\mathrm{A}+\mathrm{C}]^{n_{\mathrm{B}}} K_{\mathrm{B}}+K_{\mathrm{A}}^{n_{\mathrm{B}}} K_{\mathrm{B}}+K_{\mathrm{A}}^{n_{\mathrm{B}}}[\mathrm{B}]+\alpha[\mathrm{A}+\mathrm{C}]^{n_{\mathrm{B}}}[\mathrm{B}]\right)^{n_{\mathrm{T}}}+\left\{\tau_{\mathrm{A}}[\mathrm{A}]^{n_{\mathrm{B}}}\left(K_{\mathrm{B}}+\alpha \beta[\mathrm{B}]\right)+\tau_{\mathrm{B}}[\mathrm{B}] K_{\mathrm{A}}^{n_{\mathrm{B}}}\right\}^{n_{\mathrm{T}}}}
$$

where all other parameters are as described for eq. 4.

The Hill equation (Eq 9) was fitted to simulated data:

$$
\text { Effect }=\frac{[\mathrm{A}]^{n_{\mathrm{H}}} E_{\max }}{[\mathrm{A}]^{n_{\mathrm{H}}}+\mathrm{EC}_{50}^{n_{\mathrm{H}}}}
$$

where $[\mathrm{A}]$ is the agonist concentration; $E_{\max }$ is the maximum agonist effect; and $n_{\mathrm{H}}$ is the Hill slope.

Nonlinear regression analysis was performed in GraphPad Prism 7 or 8. Potency, affinity, cooperativity, and efficacy parameters were concentration-response profile predicted with the two different operational models of agonism. Specifically, the Black-Leff model predicts that high-efficacy agonists have greater potency relative to affinity (due to amplification of the steps between agonist binding and response), while for low-efficacy agonists, the $\mathrm{EC}_{50}$ value may be less than the $K_{\mathrm{A}}$ value for curves that possess nonunity Hill slopes. The latter was previously noted by Black et al. (1985). Furthermore, the Hill slope decreases alongside decreases in $\tau_{\mathrm{A}}$. In comparison, the 
TABLE 1

Simulation of agonist concentration-response relationships upon changes in binding or transducer slopes and $\tau_{\mathrm{A}}$

Data were simulated using the cooperative agonist operational model (eq. 2) and a Hill equation (eq. 9) was fitted to simulated data to determine agonist potency, maximum effect, and Hill slope.

\begin{tabular}{|c|c|c|c|c|c|c|c|c|c|c|c|c|}
\hline \multirow{3}{*}{ Parameter } & \multicolumn{12}{|c|}{ eq. 2} \\
\hline & \multicolumn{3}{|c|}{$n_{\mathrm{B}} 0.5$} & \multicolumn{3}{|c|}{$n_{\mathrm{B}} 1$} & \multicolumn{3}{|c|}{$n_{\mathrm{B}} 2$} & \multicolumn{3}{|c|}{$n_{\mathrm{B}} 3$} \\
\hline & $\mathrm{pEC}_{50}$ & $E_{\max }$ & $n_{\mathrm{H}}$ & $\mathrm{pEC}_{50}$ & $E_{\max }$ & $n_{\mathrm{H}}$ & $\mathrm{pEC}_{50}$ & $E_{\max }$ & $n_{\mathrm{H}}$ & $\mathrm{pEC}_{50}$ & $E_{\max }$ & $n_{\mathrm{H}}$ \\
\hline \multicolumn{13}{|l|}{$\tau_{\mathrm{A}} 1$} \\
\hline$n_{\mathrm{T}} 0.5$ & 4.8 & 51 & 0.3 & 3.9 & 50 & 0.7 & 3.4 & 50 & 1.3 & 3.3 & 50 & 2.0 \\
\hline$n_{\mathrm{T}} 1$ & 3.5 & 51 & 0.5 & 3.2 & 51 & 1.0 & 3.1 & 51 & 2.0 & 3.0 & 51 & 3.0 \\
\hline$n_{\mathrm{T}} 2$ & 2.6 & 51 & 0.6 & 2.8 & 51 & 1.3 & 2.8 & 51 & 2.4 & 2.9 & 51 & 3.5 \\
\hline$n_{\mathrm{T}} 1$ & 4.2 & 76 & 0.5 & 3.5 & 76 & 1.0 & 3.2 & 76 & 2.0 & 3.1 & 76 & 3.0 \\
\hline$n_{\mathrm{T}} 2$ & 3.7 & 90 & 0.8 & 3.3 & 90 & 1.5 & 3.1 & 91 & 3.3 & 3.1 & 91 & 4.9 \\
\hline$n_{\mathrm{T}} 3$ & 3.6 & 96 & 1.1 & 3.3 & 97 & 2.1 & 3.1 & 97 & 4.7 & 3.0 & 97 & 6.0 \\
\hline
\end{tabular}

$\mathrm{pEC}_{50}$, agonist potency.

cooperative agonist operational model predicts that when $n_{\mathrm{T}}=1$, agonist $\mathrm{EC}_{50}$ may approach but not be less than its $K_{\mathrm{A}}$ value, regardless of whether $n_{\mathrm{B}}>1$, and there is no effect of $\tau_{\mathrm{A}}$ on the Hill slope of the agonist concentration-response curve (Fig. 2; Table 2).

Quantification of Experimentally Derived Agonist Concentration-Response Data. We next tested whether our simulations were recapitulated in a functional assay that measures CaSR activation. To do so, we measured $\mathrm{Ca}_{\mathrm{o}}^{2+}$-mediated $\mathrm{Ca}_{\mathrm{i}}^{2+}$ mobilization following titration of CaSR expression using a tetracycline inducible system. In the absence of tetracycline, the maximal response to $\mathrm{Ca}_{\mathrm{o}}^{2+}$ is approximately $50 \%$ of the maximal response obtained under full induction of receptor expression (100 $\mathrm{ng} / \mathrm{ml}$ tetracycline). In this system, fitting a Hill equation (eq. 9) to both data sets indicated that the data were fitted best when the Hill slope was unchanged with different receptor expression levels, i.e., different magnitudes of $\tau_{\mathrm{A}}(P<0.05$, extra sum-of-squares $F$ test; data not shown). For the CaSR, the small molecule allosteric agonists 1-(1,3-benzothiazol-2-yl)-1-(2,4-dimethylphenyl)ethanol (AC265347) and $R$-1-(6-methoxy-4' -(trifluoromethyl)-3-biphenylyl)-N-( $R$ )- 1-phenylethyl)ethanamine (calcimimetic B) activate the CaSR with a Hill slope of 1
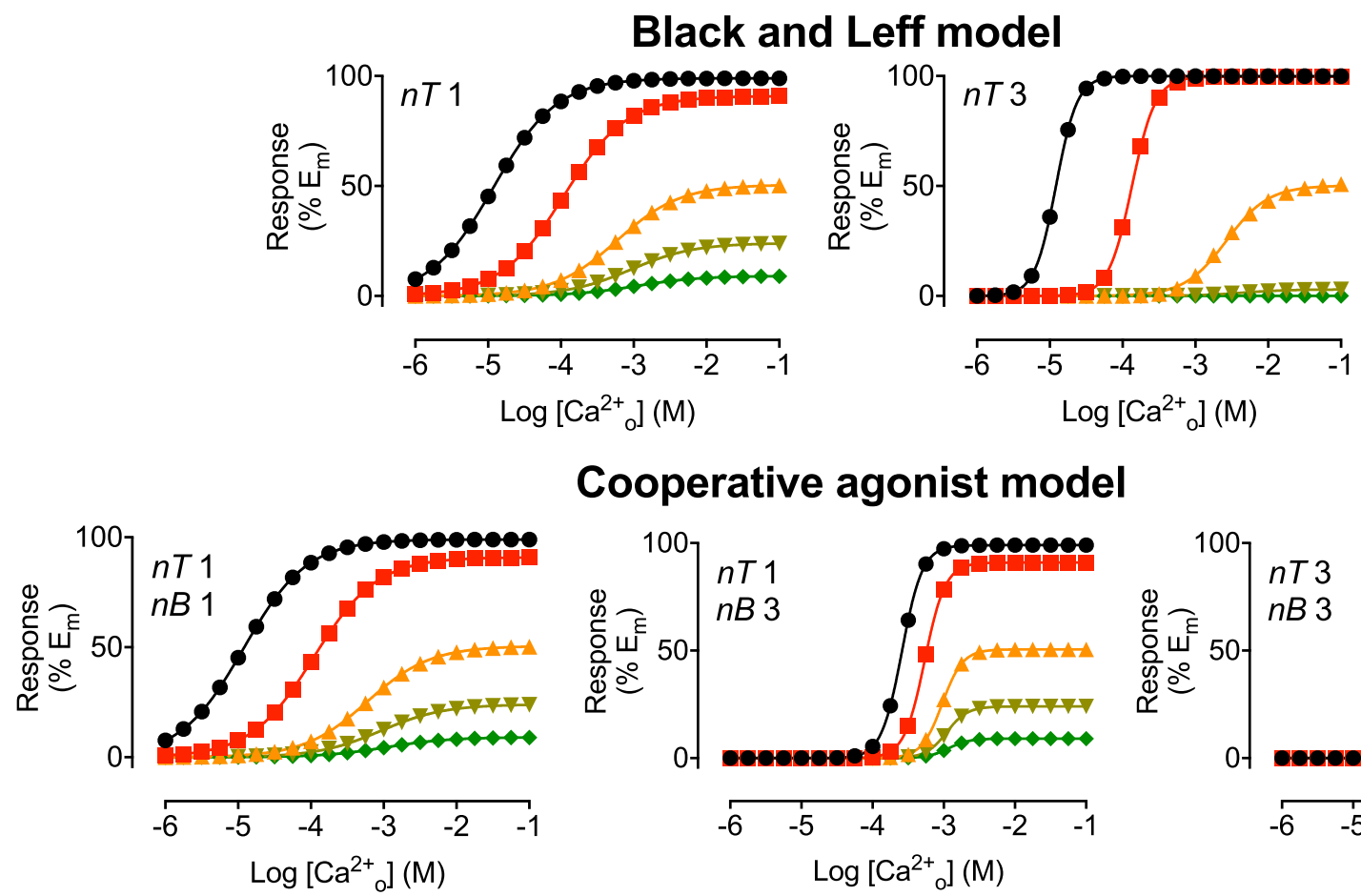

\section{Cooperative agonist model}
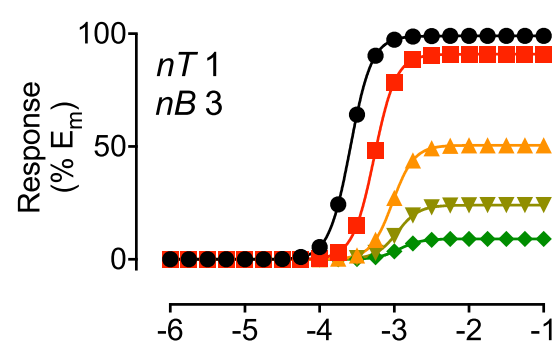

$\log \left[\mathrm{Ca}^{2+}\right](\mathrm{M})$

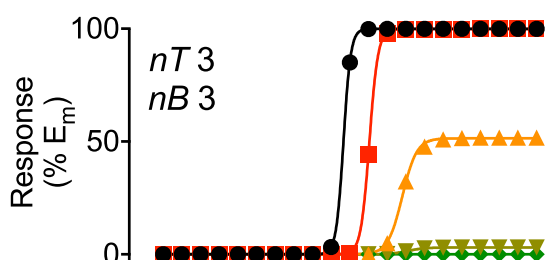

\begin{tabular}{llllll}
\hline-6 & -5 & -4 & -3 & -2 & -1
\end{tabular}

$\log \left[\mathrm{Ca}^{2+}\right](\mathrm{M})$

$$
\tau=100
$$

$$
\tau=1
$$$$
\tau=0.3
$$

$$
\tau=0.1
$$

Fig. 2. Cooperative agonist binding influences agonist concentration-response relationships. Simulations demonstrating the influence of agonist efficacy $\left(\tau_{\mathrm{A}}\right)$ on agonist concentration-response relationships when the slope is governed by the transducer slope $\left(n_{\mathrm{T}}\right.$, Black-Leff operational model of agonism) or the agonist binding slope ( $n_{\mathrm{B}}$, cooperative agonist operational model). Data were simulated using the Black-Leff model (eq. 1) or the cooperative agonist operational model (eq. 2), where the affinity of the agonist $\left(K_{\mathrm{A}}\right)$ is $1.2 \mathrm{mM}$ and $n_{\mathrm{T}}$ and $n_{\mathrm{B}}$ are between 1 and 3. Curves through the data are the fits to a Hill equation (eq. 9), where the parameters describing the fits are given in Table 2. 
TABLE 2

Simulation of agonist concentration-response relationships upon changes in binding or transducer slopes and $\tau_{\mathrm{A}}$

Data were simulated using the Black-Leff model (eq. 1) or the cooperative agonist operational model (eq. 2) and a Hill equation (eq. 9) was fitted to simulated data to determine agonist potency, maximum effect, and Hill slope.

\begin{tabular}{|c|c|c|c|c|c|c|c|c|c|c|c|c|c|c|c|}
\hline \multirow{2}{*}{$\tau_{\mathrm{A}}$} & \multicolumn{3}{|c|}{ eq. $1 ; n_{\mathrm{T}} 1$} & \multicolumn{3}{|c|}{ eq. $1 ; n_{\mathrm{T}} 3$} & \multicolumn{3}{|c|}{ eq. $2 ; n_{\mathrm{T}} 1, n_{\mathrm{B}} 1$} & \multicolumn{3}{|c|}{ eq. $2 ; n_{\mathrm{T}} 1, n_{\mathrm{B}} 3$} & \multicolumn{3}{|c|}{ eq. $2 ; n_{\mathrm{T}} 3, n_{\mathrm{B}} 3$} \\
\hline & $\mathrm{pEC}_{50}$ & $E_{\max }$ & $n_{\mathrm{H}}$ & $\mathrm{pEC}_{50}$ & $E_{\max }$ & $n_{\mathrm{H}}$ & $\mathrm{pEC}_{50}$ & $E_{\max }$ & $n_{\mathrm{H}}$ & $\mathrm{pEC}_{50}$ & $E_{\max }$ & $n_{\mathrm{H}}$ & $\mathrm{pEC}_{50}$ & $E_{\max }$ & $n_{\mathrm{H}}$ \\
\hline 100 & 4.9 & 99 & 1.0 & 4.9 & 100 & 3.0 & 4.9 & 99 & 1.0 & 3.6 & 99 & 3.0 & 3.6 & 100 & 8.9 \\
\hline 10 & 4.0 & 91 & 1.0 & 3.9 & 100 & 2.7 & 4.0 & 91 & 1.0 & 3.3 & 91 & 3.0 & 3.2 & 100 & 7.6 \\
\hline 1 & 3.2 & 51 & 1.0 & 2.6 & 50 & 1.5 & 3.2 & 51 & 1.0 & 3.0 & 51 & 3.0 & 2.8 & 51 & 4.5 \\
\hline 0.3 & 3.0 & 24 & 1.0 & 2.4 & 3.0 & 1.4 & 3.0 & 24 & 1.0 & 3.0 & 24 & 3.0 & 2.7 & 3.0 & 3.9 \\
\hline 0.1 & 3.0 & 9.0 & 1.0 & 2.3 & 0.1 & 1.4 & 3.0 & 9.0 & 1.0 & 3.0 & 9.0 & 3.0 & 2.7 & 0.1 & 3.8 \\
\hline
\end{tabular}

$\mathrm{pEC}_{50}$, agonist potency.

(Cook et al., 2015; Keller et al., 2018). Similarly, when cooperative agonist binding is prevented by removal of the CaSR's N-terminal domain, and consequently the primary $\mathrm{Ca}_{\mathrm{o}}^{2+}$ binding sites, the Hill slope for $\mathrm{Ca}_{\mathrm{o}}^{2+}$ is not significantly different from unity (as shown subsequently). This provides experimental evidence that the CaSR's transducer slope is equal to unity, and that the steep Hill slopes observed for $\mathrm{Ca}_{\mathrm{o}}^{2+}$ at the full-length CaSR thus likely arise from a binding slope greater than 1 . Thus, when fitting CaSR experimental data to the cooperative agonist operational model, $n_{\mathrm{T}}$ was constrained to unity.

When the data were fitted to the classic Black-Leff model, the estimated $K_{\mathrm{A}}$ value was $0.2 \mathrm{mM}$ (Fig. 3A; Table 3). In comparison, the cooperative agonist operational model yielded a $K_{\mathrm{A}}$ estimate of $1.1 \mathrm{mM}$, which is in close agreement with the $\mathrm{EC}_{50}$ value $(1.2 \mathrm{mM})$ of $\mathrm{Ca}_{0}^{2+}$ for suppressing parathyroid hormone release (Brown, 1983) and $\mathrm{Ca}_{0}^{2+}$ affinity estimates for the CaSR extracellular domain determined using spectroscopic approaches (Huang et al., 2009; Zhang et al., 2014). For both analyses, data were fitted best when the binding slope (cooperative agonist operational model) or transducer slope (Black-Leff model) were different from unity $(P<0.05$, extra sum of squares $F$ test).

To further validate our simulations in a functional assay, we next sought to quantify the affinity and efficacy of a CaSR partial agonist. To do so, we took advantage of observations that in comparison with at the WT CaSR (Fig. 3B), $\mathrm{Ca}_{\mathrm{o}}^{2+}$ acting via the 7 transmembrane domain is a partial agonist at an $\mathrm{N}$-terminally truncated CaSR (depicted in Fig. 3C) relative to the extracellular trivalent gadolinium cation (Fig. 3D). The fluorescence-activated cytometry analysis confirmed cell surface expression of the WT and N-terminally truncated CaSR (Supplemental Fig. 1). We quantified $\mathrm{Ca}_{\mathrm{o}}^{2+}$ affinity and efficacy at the $\mathrm{N}$-terminally truncated CaSR using the original Black-Leff model or the cooperative agonist operational model (Table 3). In both instances, data were best fitted when the binding slope (the cooperative agonist operational model) or transducer slope (the Black-Leff model) were not different from unity $(P<0.05$, extra sum of squares $F$ test), which is consistent with a reduction in positively cooperative $\mathrm{Ca}_{\mathrm{o}}^{2+}$ binding, as would be expected upon removal of the four primary $\mathrm{Ca}_{0}^{2+}$ binding sites located in the $\mathrm{N}$-terminal domain (Geng et al., 2016). Thus, the parameters determined at the $\mathrm{N}$-terminally truncated receptor were identical regardless of the equation used to analyze the data. The $\mathrm{Ca}_{0}^{2+}$ affinity and cooperativity estimates at the N-terminally truncated receptor were compared with those determined at the full-length WT CaSR, indicating a reduction in $\mathrm{Ca}_{0}^{2+}$ affinity at the $\mathrm{N}$-terminally truncated receptor in comparison with WT (Table 3), again consistent with removal of the primary
A

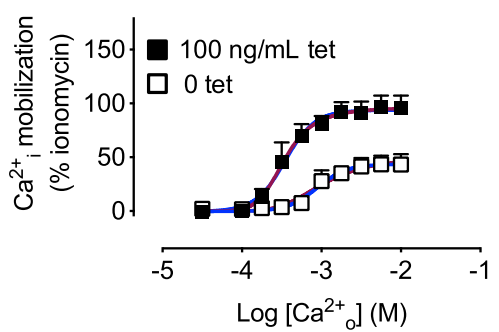

C

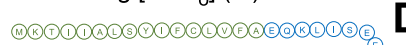

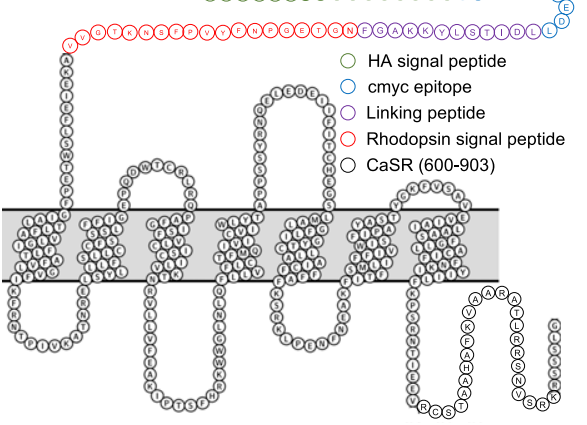

B

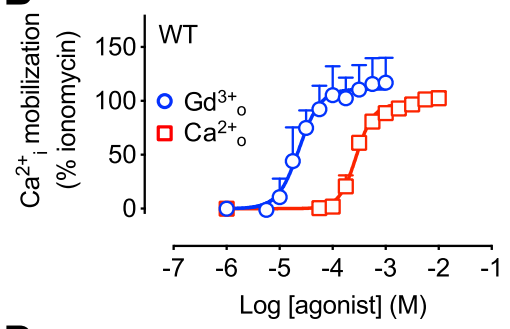

D

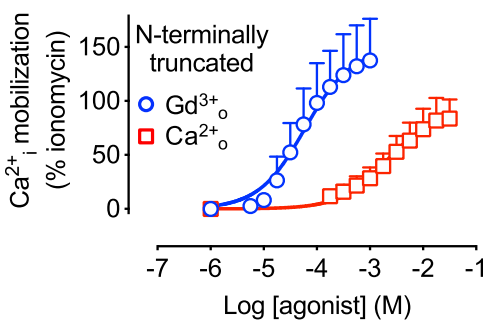

Fig. 3. $\mathrm{Ca}_{0}^{2+}-\mathrm{CaSR}$ concentration-response relationships fit well to the cooperative agonist operational model. (A) $\mathrm{Ca}_{0}^{2+}$-mediated $\mathrm{Ca}_{\mathrm{i}}^{2+}$ mobilization at the WT CaSR following overnight receptor induction with $100 \mathrm{ng} / \mathrm{ml}$ tetracycline (tet) or in the absence of tetracycline. Data are mean + S.D. from four independent experiments performed in duplicate. Curves through the data are the fits to the Black-Leff model (blue line) or the cooperative agonist operational model (red line), where the parameters describing the fits are given in Table 3. Although both models fit the data, the cooperative agonist operational model more accurately predicts the expected affinity of $\mathrm{Ca}_{0}^{2+}$ at the CaSR (Table 3). (B) Extracellular trivalent gadolinium $\left(\mathrm{Gd}_{0}^{3+}\right)$ and $\mathrm{Ca}_{o}^{2+}$ concentration-response curves at the WT CaSR following overnight receptor induction with $100 \mathrm{ng} / \mathrm{ml}$ tetracycline. Data are mean + S.D. from four independent experiments performed in duplicate. Curves through the data are the fits to a four-parameter Hill equation. (C) N-terminally truncated CaSR snake diagram. (D) $\mathrm{Gd}_{\mathrm{o}}^{3+}$ and $\mathrm{Ca}_{\mathrm{o}}^{2+}$ concentration-response curves at an N-terminally truncated CaSR following overnight receptor induction with $100 \mathrm{ng} / \mathrm{ml}$ tetracycline. Data are mean + S.D. from five independent experiments performed in duplicate. Curves through the data are the fits to the cooperative agonist operational model, where the parameters describing the fits are given in Table 3. 
TABLE 3

Quantification of $\mathrm{Ca}_{\mathrm{o}}^{2+}$ affinity and efficacy for $\mathrm{CaSR}-\mathrm{Ca}_{\mathrm{i}}^{2+}$ mobilization using the operational model of agonism

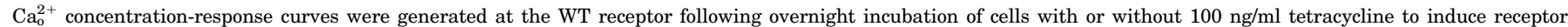

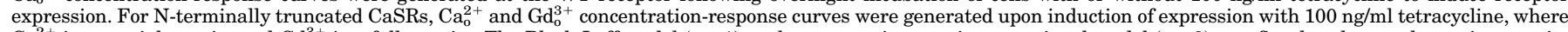

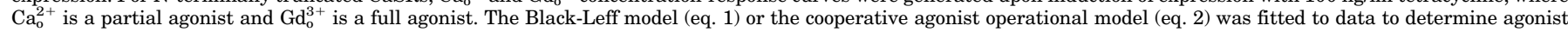
affinity, efficacy, and transducer or binding slope.

\begin{tabular}{|c|c|c|c|c|}
\hline \multirow{2}{*}{ Parameter } & \multicolumn{2}{|c|}{ WT } & \multicolumn{2}{|c|}{ N-terminally truncated CaSR } \\
\hline & eq. 1 & eq. 2 & eq. 1 & eq. 2 \\
\hline $\begin{array}{r}\mathrm{p} K_{\mathrm{A}}\left[K_{\mathrm{A}}\right. \\
(\mathrm{mM})]\end{array}$ & $3.7 \pm 0.3(0.2)$ & $3.0 \pm 0.1(1.0)$ & $2.3 \pm 0.2(5.0)$ & $2.3 \pm 0.2(5.0)$ \\
\hline $\log \tau_{\mathrm{A}}\left(\tau_{\mathrm{A}}\right)$ & $100 \mathrm{ng} / \mathrm{ml}$ tet: $0.2 \pm \underset{(1.0)}{0.1(1.6)} 0$ tet: $-0.01 \pm 0.01$ & $100 \mathrm{ng} / \mathrm{ml}$ tet: $1.2 \pm \underset{(0.8)}{0.2(16)} 0$ tet: $-0.1 \pm 0.1$ & $0.2 \pm 0.1(1.6)$ & $0.2 \pm 0.1(1.6)$ \\
\hline$n$ & $6.0 \pm 3.0^{a}$ & $2.0 \pm 0.3^{a}$ & $1.0^{b}$ & $1.0^{b}$ \\
\hline
\end{tabular}

Dfd, degrees of freedom denominator; Dfn, degrees of freedom numerator; Log $\tau_{\mathrm{A}}\left(\tau_{\mathrm{A}}\right)$, efficacy; $n$, transducer or binding slope; $\mathrm{p} K_{\mathrm{A}}\left(K_{\mathrm{A}}\right)$, agonist affinity; tet, tetracycline.

${ }^{a} \mathrm{An} F$ test determined that data were fitted best when the binding or transducer slopes were different from unity. The $F$ data used to test the hypothesis that $n$ differed from 1 were the following: eq. $1 P<0.0001, F$ [(Dfn, Dfd) 48.57 (1, 74)]; and eq. $2 P<0.0001, F$ [(Dfn, Dfd) 45.78 (1, 74)].

${ }^{b}$ An $F$ test determined that data were fitted best when the binding or transducer slopes were not different from unity. The $F$ data used to test the hypothesis that $n$ differed from 1 were the following: eq. $1 P<0.2282, F[(\mathrm{Dfn}, \mathrm{Dfd}) 1.470(1,101)]$; and eq. $2 P<0.5332, F[(\mathrm{Dfn}, \mathrm{Dfd}) 0.3910$ (1, 101)].

$\mathrm{Ca}_{\mathrm{o}}^{2+}$ binding sites. However, due to a lower estimate of $\mathrm{Ca}_{\mathrm{o}}^{2+}$ efficacy at the WT receptor when WT data were analyzed using the Black-Leff model, only the cooperative agonist operational model accurately quantified a reduction in $\mathrm{Ca}_{\mathrm{o}}^{2+}$ efficacy at the N-terminally truncated receptor in comparison with at the WT receptor. This is consistent with a lower $\mathrm{Ca}_{0}^{2+} E_{\text {max }}$ value at the $\mathrm{N}$-terminally truncated receptor ( $\sim 60 \%$ of the maximum response stimulated by extracellular trivalent gadolinium) in comparison with WT $(\sim 100 \%$ extracellular trivalent gadolinium $E_{\max }$ ) (Table 3 ). Thus, only the cooperative agonist operational model accurately estimated $\mathrm{Ca}_{0}^{2+}$ partial agonism at the N-terminally truncated receptor.

Quantifying Allosteric Interactions in Systems with Different Degrees of Cooperative Agonist Binding. Having established that the cooperative agonist operational model best fitted our $\mathrm{Ca}_{\mathrm{o}}^{2+}$-WT CaSR concentration-response curves with Hill slopes greater than 1, we next extended this model to allow for quantification of allosteric modulation of an agonist response. The operational model of agonism and allosterism (Leach et al., 2007, 2010) (referred to herein as the original operational model of agonism and allosterism), which takes into account the allosteric effects on agonist affinity and efficacy, combines the allosteric ternary complex models developed by Stockton et al. (1983) and Ehlert (1988) and the Black-Leff operational model of agonism. In our original model (Leach et al., 2007), the allosteric modulator can also possess intrinsic efficacy. Introduction of a slope in that model once again assumed that the slope linked occupancy to response, not to the original binding events, which were assumed to be described as simple one-to-one hyperbolic functions. Therefore, we adapted this operational model of allosterism to account for cooperative agonist binding, referred to hereinafter as the operational model of allosterism with cooperative agonist binding. To validate this operational model of allosterism with cooperative agonist binding, we reanalyzed existing data demonstrating positive and negative allosteric modulation at three model GPCRs with different agonist Hill slopes: CaSR (a class C GPCR where the primary endogenous agonist, $\mathrm{Ca}_{\mathrm{o}}^{2+}$, has a Hill slope of $\left.2-4\right), \mathrm{mGlu}_{5}$ (a class C GPCR where the primary endogenous agonist, L-glutamate, has a Hill slope of 1.8) (Sengmany and Gregory, 2016), and $\mathrm{M}_{4} \mathrm{mAChR}$ (a class A GPCR where the endogenous agonist, acetylcholine, has a Hill slope of 1) (Leach et al., 2010, 2011) (Supplemental Fig. 2). In all instances, $n_{\mathrm{T}}$ was assumed to be unity and all allosteric modulators were assumed to bind to a single site (i.e., the modulator binding slope is unity).

For the CaSR, we analyzed allosteric modulation of $\mathrm{Ca}_{\mathrm{o}}^{2+}$ by cinacalcet (PAM) or NPS2143 (NAM) (Leach et al., 2016) with the original operational model of agonism and allosterism with contaminating (i.e., ambient buffer) agonist (eqs. 5 or 6 , respectively) and the newly derived operational model of allosterism with cooperative agonist binding and contaminating agonist (eqs. 7 or 8, respectively) (Fig. 4). Similar to our analysis of agonist concentration-response curves, data were fitted best when the binding slope (operational model of allosterism with cooperative agonist binding) or transducer slope (original operational model of agonism and allosterism) was different from unity ( $P<0.05$, extra sum of squares $F$ test). Compared with the original operational model of agonism and allosterism, the estimated affinity for $\mathrm{Ca}_{\mathrm{o}}^{2+}$ determined using the operational model of allosterism with cooperative agonist binding (1.4 mM) (Table 4) was once again closer to the assumed $\mathrm{Ca}_{\mathrm{o}}^{2+}$ affinity based on its $\mathrm{EC}_{50}$ value for suppression of parathyroid hormone release $(1.2 \mathrm{mM})$ and quantification of the $\mathrm{Ca}_{\mathrm{o}}^{2+} K_{\mathrm{A}}$ at the extracellular domain using spectroscopic approaches (3-5 mM) (Huang et al., 2009; Zhang et al., 2014). Furthermore, the estimated affinity and negative cooperativity of NPS2143 were greater (5.5- and 35-fold, respectively) when cooperative agonist binding was factored into the analysis (Table 4). For the PAM, cinacalcet,
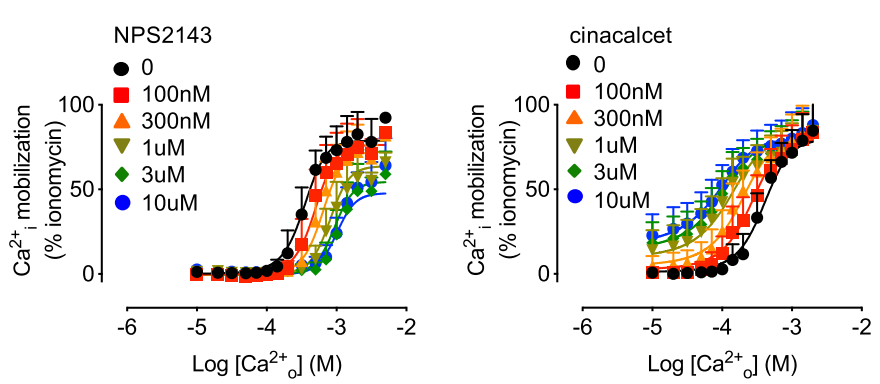

Fig. 4. Allosteric modulation at the CaSR is fitted well by an operational model of allosterism with cooperative agonist binding. Allosteric modulation of $\mathrm{Ca}_{\mathrm{o}}^{2+}$-mediated $\mathrm{Ca}_{\mathrm{i}}^{2+}$ mobilization at the CaSR by NPS2143 (NAM) or cinacalcet (PAM). Data were previously published (Leach et al., 2016) and are mean + S.D. from at least 11 independent experiments performed in duplicate. Curves through the data are the fits to the operational model of allosterism with cooperative agonist binding and contaminating agonist (eq. 7 for cinacalcet and eq. 8 for NPS2143), where the parameters describing the fits are given in Table 4. 
TABLE 4

Comparison of parameters describing CaSR allosteric interactions analyzed with different allosteric models

CaSR allosteric interactions with $\mathrm{Ca}_{\mathrm{o}}^{2+}$ in $\mathrm{Ca}_{\mathrm{i}}^{2+}$ mobilization assays were analyzed with the original operational model of agonism and allosterism (eqs. 5 or 6 ) vs. the operational model of allosterism with cooperative agonist binding (eqs. 7 or 8 ) to determine $\mathrm{Ca}_{\mathrm{o}}^{2+}$ potency, efficacy, and affinity; modulator affinity, cooperativity, and transducer or binding slope; and maximum system response.

\begin{tabular}{|c|c|c|c|c|}
\hline \multirow{2}{*}{ Parameter } & \multicolumn{2}{|c|}{$\mathrm{Ca}_{\mathrm{o}}^{2+}$ vs. Cinacalcet } & \multicolumn{2}{|c|}{$\mathrm{Ca}_{\mathrm{o}}^{2+}$ vs. NPS2143 } \\
\hline & eq. 5 & eq. 7 & eq. 6 & eq. 8 \\
\hline $\mathrm{pEC}_{50}$ & $3.3 \pm 0.01$ & $3.3 \pm 0.01$ & n.d. & n.d. \\
\hline $\mathrm{p} K_{\mathrm{A}}\left[K_{\mathrm{A}}(\mathrm{mM})\right]$ & n.d. & n.d. & $3.6 \pm 0.2(0.3)$ & $2.9 \pm 0.1(1.3)$ \\
\hline $\mathrm{p} K_{\mathrm{B}}\left[K_{\mathrm{B}}(\mu \mathrm{M})\right]$ & $6.3 \pm 0.04(0.5)$ & $5.8 \pm 0.1(1.6)$ & $6.6 \pm 0.04(0.3)$ & $7.3 \pm 0.1(0.05)$ \\
\hline $\log \tau_{\mathrm{A}}\left(\tau_{\mathrm{A}}\right)$ & n.d. & n.d. & $0.2 \pm 0.1(1.6)$ & $1.8 \pm 0.1(63)$ \\
\hline $\log \tau_{\mathrm{B}}\left(\tau_{\mathrm{B}}\right)$ & n.a. $(0)$ & n.a. (0) & n.a. $(0)$ & n.a. $(0)$ \\
\hline $\log \alpha \beta(\alpha \beta)$ & $0.5 \pm 0.01(3.2)$ & $1.4 \pm 0.1(25)$ & $-0.2 \pm 0.1(0.6)$ & $-1.7 \pm 0.1(0.02)$ \\
\hline$n$ & $2.8 \pm 0.1^{a}$ & $2.8 \pm 0.1^{a}$ & $12 \pm 4.0^{a}$ & $3.5 \pm 0.2^{a}$ \\
\hline$E_{\mathrm{m}}(\%$ ionomycin $)$ & $79 \pm 1.0$ & $80 \pm 1.0$ & $78 \pm 1.0$ & $80 \pm 2$ \\
\hline
\end{tabular}

Dfd, degrees of freedom denominator; Dfn, degrees of freedom numerator; $E_{\mathrm{m}}$, maximum system response; Log $\alpha \beta(\alpha \beta)$, modulator cooperativity; $\log \tau_{\mathrm{A}}\left(\tau_{\mathrm{A}}\right), \mathrm{Ca}_{\mathrm{o}}^{2+}$ efficacy; $\log \tau_{\mathrm{B}}\left(\tau_{\mathrm{B}}\right)$, modulator efficacy; $\mathrm{Ca}_{\mathrm{o}}^{2+}$ efficacy; $n$, transducer or binding slope; n.a., no agonist activity $\left[\log \tau_{\mathrm{B}}\right.$ fixed to $\left.-100\left(\tau_{\mathrm{B}} 0\right)\right]$; n.d., not determined; $\mathrm{pEC}_{50}, \mathrm{Ca}_{0}^{2+}$ potency; $K_{\mathrm{A}}\left(K_{\mathrm{A}}\right), \mathrm{Ca}_{0}^{2+}$ affinity; $K_{\mathrm{B}}\left(K_{\mathrm{B}}\right)$, modulator affinity

${ }^{a}$ An $F$ test determined that data were fitted best when the transducer or binding slopes were different from unity. The $F$ data used to test the hypothesis that $n$ differed from 1 were the following: eq. 5 cinacalcet $P<0.0001, F$ [(Dfn, Dfd) 1249 (1, 2429)]; eq. 5 NPS2143 $P<0.0001, F$ [(Dfn, Dfd) $1022(1,908]$; eq. 7 cinacalcet $P<0.0001, F$ [(Dfn, Dfd) 1241 (1, 2429)]; and eq. 7 NPS2143 $P<0.0001, F$ [(Dfn, Dfd) $504.5(1,907)]$.

the operational model of allosterism with cooperative agonist binding yielded a 3 -fold lower affinity estimate but an 8-fold greater magnitude of positive cooperativity.

We next analyzed allosteric modulation of glutamate at $\mathrm{mGlu}_{5}$ (eqs. 3 or 4 ) by a representative full NAM (2-methyl-6(2-phenylethynyl)pyridine [MPEP]) that completely inhibits glutamate-mediated activation of $\mathrm{Ca}_{\mathrm{i}}^{2+}$ mobilization, a partial NAM (2-[2-(3-methoxyphenyl)ethynyl]-5-methylpyridine [M$5 \mathrm{MPEP}]$ ) that only partially inhibits glutamate-mediated activation of $\mathrm{Ca}_{\mathrm{i}}^{2+}$ mobilization (Sengmany et al., 2019), a pure PAM ( $N$-(1,3-Diphenyl-1H-pyrazolo-5-yl)-4-nitrobenzamide [VU-29]), and a mixed PAM-agonist (1-(4-(2,4-difluorophenyl)piperazin-1-yl)-2-((4-fluorobenzyl)oxy)ethanone [DPFE]) (Sengmany et al., 2017). Similar to analyses at the CaSR, all data were fitted best when the binding slope (operational model of allosterism with cooperative agonist binding) or transducer slope (original operational model of agonism and allosterism) was different from unity $(P<0.05$, extra sum of squares $F$ test). However, for each modulator, the affinity and cooperativity estimates were similar (within 3-fold) irrespective of the analytical model applied (Fig. 5; Table 5). Therefore, although the glutamate-mGlu concentration-response relationship has a Hill slope greater than unity, quantification of allosteric interactions at $\mathrm{mGlu}_{5}$ is largely unaffected by whether the empirical slope is assumed to be determined by the transducer slope or the agonist binding slope.

For the $\mathrm{M}_{4} \mathrm{mAChR}$, we analyzed previously published positive allosteric modulation of ACh by the PAM agonist LY2033298 in guanosine $5^{\prime}-O-\left(3-\left[{ }^{35} \mathrm{~S}\right]\right.$ thio $)$ triphosphate binding assays (Leach et al., 2010) (eqs. 3 or 4). As expected, in the absence of cooperative ACh binding at the $\mathrm{M}_{4} \mathrm{mAChR}$, data for the interaction between ACh and LY2033298 were fitted best by both operational models of agonism and allosterism when the slope was not different from unity $(P<0.05$, extra sum of squares $F$ test); therefore, both equations yielded identical estimates of affinity and cooperativity (Fig. 6; Table 6).

We next sought to establish why quantification of PAM and NAM affinity and cooperativity were not greatly affected by the assignment of the slope at $\mathrm{mGlu}_{5}$, where the glutamate Hill slope is greater than unity. To do so, we simulated the interaction between an orthosteric agonist and a NAM or PAM with the operational model of allosterism with cooperative agonist binding and analyzed the simulated data with the original operational model of agonism and allosterism. For these simulations, orthosteric agonist affinity $(1 \mu \mathrm{M}), \tau_{\mathrm{A}}(10)$, and modulator affinity (10 nM) were held constant, and different magnitudes of positive or negative cooperativity were examined alongside changes in the magnitude of cooperative agonist binding. Consistent with our analysis of $\mathrm{mGlu}_{5}$ allosteric interaction data, when the agonist binding
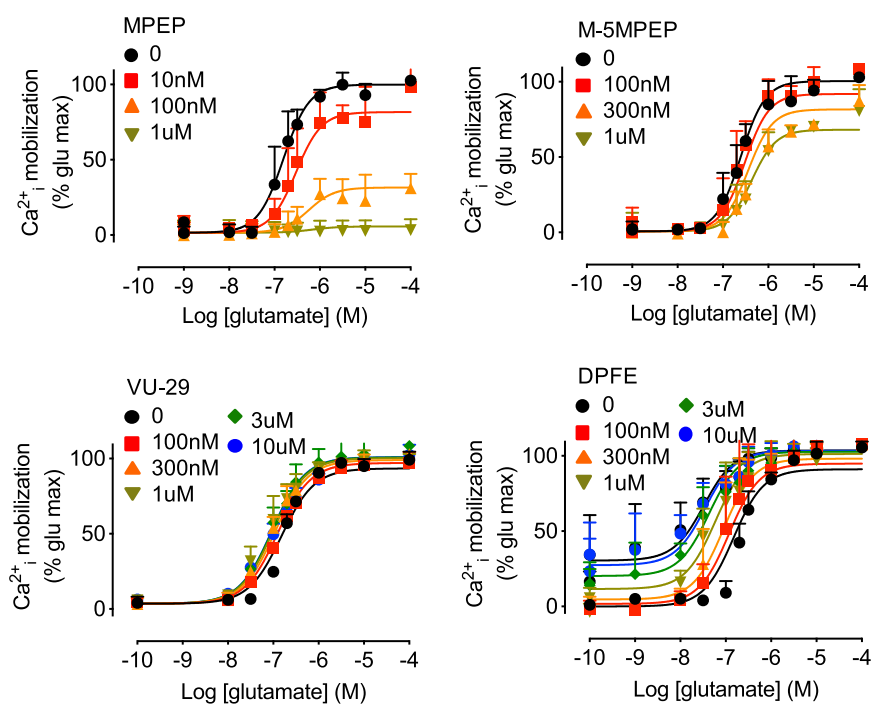

Fig. 5. Allosteric modulation at $\mathrm{mGlu}_{5}$ is fitted well by an operational model of allosterism with cooperative agonist binding. Allosteric modulation of glutamate-mediated $\mathrm{Ca}_{i}^{2+}$ mobilization at mGlu 5 by MPEP (full NAM), M-5MPEP (partial NAM), VU-29 (PAM), and DPFE (ago-PAM). Data were previously published (Sengmany et al., 2017, 2019) and are mean + S.D. from at least three independent experiments performed in duplicate previously published. Curves through the data are the fits to the operational model of allosterism with cooperative agonist binding (eq. 4), where the parameters describing the fits are given in Table 5. 


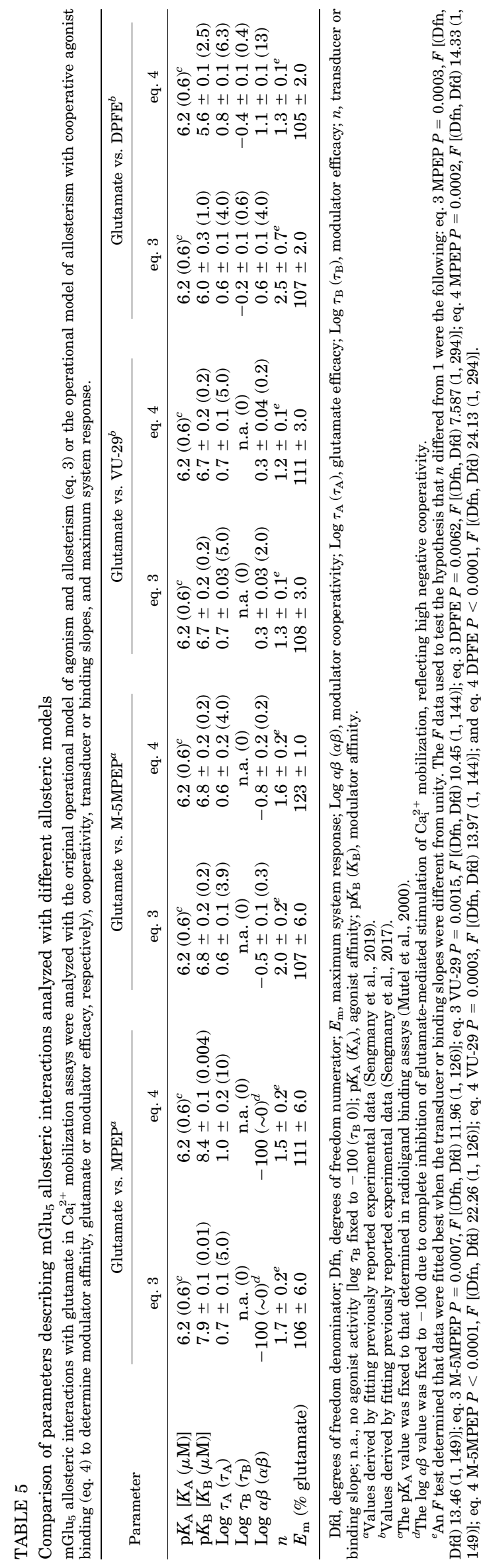

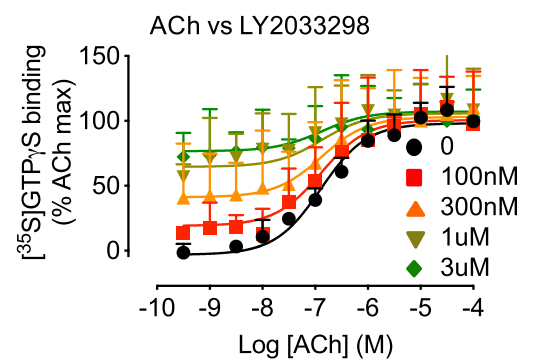

Fig. 6. Allosteric modulation at the $\mathrm{M}_{4} \mathrm{mAChR}$ is fitted well by an operational model of allosterism with no cooperative agonist binding. Positive modulation of ACh-mediated guanosine $5^{\prime}-\mathrm{O}-\left(3-{ }^{35} \mathrm{~S}\right]$ thio)triphosphate $\left(\left[{ }^{35} \mathrm{~S}\right] \mathrm{GTP} \gamma \mathrm{S}\right.$ ) binding by LY2033298 (ago-PAM) at the $\mathrm{M}_{4} \mathrm{mAChR}$. Data were previously published (Leach et al., 2010) and are mean + S.D. from at least three independent experiments performed in duplicate. Curves through the data are the fits to the operational model of allosterism with cooperative agonist binding (eq. 4), where the equation was fitted best when $n=1$ (i.e., no cooperative agonist binding). The parameters describing the fits are given in Table 6.

slope ranged from 1 to 2 the affinity of NAMs and PAMs estimated using the original operational model of agonism and allosterism fell within $\sim 3$-fold of the affinity simulated with the operational model of allosterism with cooperative agonist binding. Furthermore, only the affinity of the full NAM (where $\alpha \beta$ is assumed to approach zero) fell outside this 3-fold window once the agonist binding slope exceeded 2 (Fig. 7A). Similarly, when analyzed with the original operational model of agonism and allosterism, the $\alpha \beta$ values (0.1-10) were within a 3-fold range of simulated data when $n_{\mathrm{T}}$ ranged from 1 to 2 . However, where the magnitude of cooperativity exceeded 10 for a PAM, or 0.1 for a NAM, the influence of cooperative agonist binding becomes more pronounced (Fig. 7B). These simulations confirm that the assignment of $n$ to a transducer or binding slope would not be expected to greatly influence quantification of $\mathrm{mGlu}_{5}$ allosteric modulation of glutamate for modulators with moderate cooperativity, which is consistent with our $\mathrm{Ca}_{\mathrm{i}}^{2+}$ mobilization data.

\section{Discussion}

In the current study, we have assessed operational models of agonism and allosterism that account for receptors whose agonists bind multiple binding sites in a cooperative manner. The modified models accurately fit experimental data at an exemplar GPCR, the CaSR, which has high sensitivity for $\mathrm{Ca}_{0}^{2+}$ due to multiple $\mathrm{Ca}_{\mathrm{o}}^{2+}$ binding sites that are linked in a positively cooperative manner. We show that agonist Hill slopes that differ from unity and remain unchanged by alterations in receptor expression levels or cellular coupling efficiencies (i.e., where $\tau_{\mathrm{A}}$ differs) may be indicative of cooperative agonist binding. We demonstrate that if a steep Hill slope such as that observed at the CaSR is attributed to the transducer slope rather than to the agonist binding slope, the Black-Leff operational model of agonism underestimates agonist efficacy and overestimates agonist affinity. Extension to allosteric interactions shows the importance of accounting for cooperative agonist binding, since different models fitted to the same allosteric interaction data yield divergent modulator affinity and cooperativity estimates. For instance, the original operational model of agonism and allosterism estimates lower CaSR PAM and NAM cooperativity values and higher or lower 
TABLE 6

Comparison of parameters describing $\mathrm{M}_{4} \mathrm{mAChR}$ allosteric interactions analyzed with different allosteric models

$\mathrm{M}_{4}$ mAChR LY2033298 interactions with ACh in guanosine $5^{\prime}-O-\left(3-\left[{ }^{35} \mathrm{~S}\right]\right.$ thio $)$ triphosphate binding assays were analyzed with the original operational model of agonism and allosterism (eq. 3) or the operational model of allosterism with cooperative agonist binding (eq. 4) to determine agonist or modulator affinity, agonist or modulator efficacy, cooperativity, transducer or binding slopes, and maximum system response. Values obtained from fitting eqs. 3 and 4 to the data were identical; therefore, they are only presented in a single column.

\begin{tabular}{lc}
\hline Parameter & ACh vs. LY2033298 (eqs. 3 and 4) \\
\hline $\mathrm{p} K_{\mathrm{A}}\left[K_{\mathrm{A}}(\mu \mathrm{M})\right]$ & $6.0(1.0)^{b}$ \\
$\mathrm{pK}$ & $5.9 \pm 0.3(1.3)$ \\
$\left.\log \tau_{\mathrm{B}}(\mu \mathrm{M})\right]$ & $0.9 \pm 0.1(7.9)$ \\
$\log \tau_{\mathrm{B}}\left(\tau_{\mathrm{B}}\right)$ & $0.5 \pm 0.2(3.2)$ \\
$\log \alpha \beta(\alpha \beta)$ & $0.7 \pm 0.3(5.0)$ \\
$n$ & $1.0^{c}$ \\
$E_{\mathrm{m}}(\%$ ACh maximum) & $112 \pm 5.0$ \\
\hline
\end{tabular}

Dfd, degrees of freedom denominator; Dfn, degrees of freedom numerator; $E_{\mathrm{m}}$, maximum system response; $\log \alpha \beta(\alpha \beta)$, cooperativity; $\log \tau_{\mathrm{A}}\left(\tau_{\mathrm{A}}\right)$, agonist efficacy; $\log \tau_{\mathrm{B}}\left(\tau_{\mathrm{A}}\right)$, modulator efficacy; $n$, transducer or binding slope; $\mathrm{p} K_{\mathrm{A}}\left(K_{\mathrm{A}}\right)$, agonist affinity; $\mathrm{p} K_{\mathrm{B}}\left(K_{\mathrm{B}}\right)$, modulator affinity.

${ }^{a}$ Data analyzed are from Leach et al. (2010).

${ }^{b} \mathrm{The} \mathrm{p} K_{\mathrm{A}}$ value was fixed to that determined in radioligand binding assays (Leach et al., 2010).

${ }^{c}$ An $F$ test determined that data were fitted best when the transducer or binding slopes were not different from unity. The $F$ data used to test the hypothesis that $n$ differed from 1 were the following: eq. $3 P=0.5766, F[(\mathrm{Dfn}, \mathrm{Dfd}) 0.3129(1,172)]$; and eq. $4 P=0.4541, F[(\mathrm{Dfn}, \mathrm{Dfd}) 0.5629(1,172)]$

affinity values, respectively. Data simulations support these findings and demonstrate that the impact of cooperative binding on estimates of modulator affinity and cooperativity is more pronounced as the magnitude of modulator cooperativity or cooperative agonist binding is increased. This was evidenced by our demonstration that for $\mathrm{mGlu}_{5}$, where the glutamate Hill slope is $\sim 1.8$, differences in affinity and cooperativity are within the margin of experimental error ( $\sim 3$-fold range). Accordingly, for agonist-receptor concentration-response relationships with Hill slopes equal to unity, it does not matter whether the slope is governed by the transducer slope or the agonist binding slope.

The operational models of agonism and allosterism with cooperative agonist binding have important practical uses for analyzing data at receptors that possess multiple agonist binding sites. This is particularly true for the CaSR, but also for ion channels and other GPCRs where agonist binding coefficients differ from unity, such as GPR39, which binds at least two $\mathrm{Zn}^{2+}$ ions and responds to $\mathrm{Zn}^{2+}$ with a Hill slope of 2-3 (Storjohann et al., 2008; Sato et al., 2016). Similarly, cooperative binding can occur across a GPCR dimer, which may account for the steep Hill slope at $\mathrm{mGlu}_{5}$ demonstrated in the present study. For instance, the $\mathrm{mGlu}_{2}$ orthosteric agonist
(1S,2S,5R,6S)-2-aminobicyclo[3.1.0]hexane-2,6-dicarboxylic acid (LY354740) stabilizes conformational rearrangements of a metabotropic glutamate receptor subtype 2 and 4 heterodimer $\left(\mathrm{mGlu}_{2}-\mathrm{mGlu}_{4}\right)$ with a shallow Hill slope (Moreno Delgado et al., 2017), which is increased to unity when LY354740 is prevented from binding to the $\mathrm{mGlu}_{2}$ or $\mathrm{mGlu}_{4}$ orthosteric binding site in the dimer. In contrast, the glutamate $E_{\max }$ value is reduced when it can bind to only one of the orthosteric sites in the heterodimer (Moreno Delgado et al., 2017). These findings indicate negative (LY354740) and positive (glutamate) cooperativity across the dimer, respectively. Negative cooperative binding has also been demonstrated at several class A GPCRs dimers, including the 5-hydroxytryptamine $2 \mathrm{~A}, \mathrm{~A}_{3}$ adenosine, $\mathrm{H}_{3}$ histamine, and $\mathrm{D}_{2}$ dopamine receptors (Sinkins and Wells, 1993; Vivo et al., 2006; Brea et al., 2009; May et al., 2011). Accurate quantification of ligand affinity, efficacy, and cooperativity at such receptors using functional assays is critical, particularly where radioligand binding-based methods are not available. Indeed, there are no commercially available radioligands for the CaSR, thus pharmacological characterization, and indeed drug discovery at this receptor has generally relied upon functional measures of receptor activity to quantify drug actions. However, it must be noted that experimentally derived pharmacological data for agonists with steep Hill slopes will likely only be fitted to the cooperative agonist operational model and the operational model of allosterism with cooperative agonist binding when one of the binding or transducer slopes $\left(n_{\mathrm{B}}\right.$ or $\left.n_{\mathrm{T}}\right)$ is known and constrained as such. This was a key advantage of analyzing pharmacological data at the CaSR, where we showed experimentally that the transducer slope is 1 .

Our findings have important implications for past and present drug discovery efforts at class C GPCRs and beyond. Establishing structure-activity relationship profiles that dictate drug affinity and cooperativity is essential for predicting drug efficacy in vivo. However, underestimates of cooperativity at class $\mathrm{C}$ GPCRs with cooperative agonist binding may explain previous observations that class C GPCR allosteric modulators have limited cooperativity when compared with their class A GPCR counterparts. For example, PAMs with $\alpha \beta$ values $>100$ have been reported for class A GPCRs (Leach et al., 2010; Abdul-Ridha et al., 2014), whereas for the CaSR potentiation is at most 5 -fold for many modulators (Cook et al., 2015; Leach et al., 2016; Diepenhorst et al., 2018). Thus, for GPCRs with cooperative agonist binding, larger differences between modulator cooperativities were likely previously unappreciated. This is important because allosteric modulator
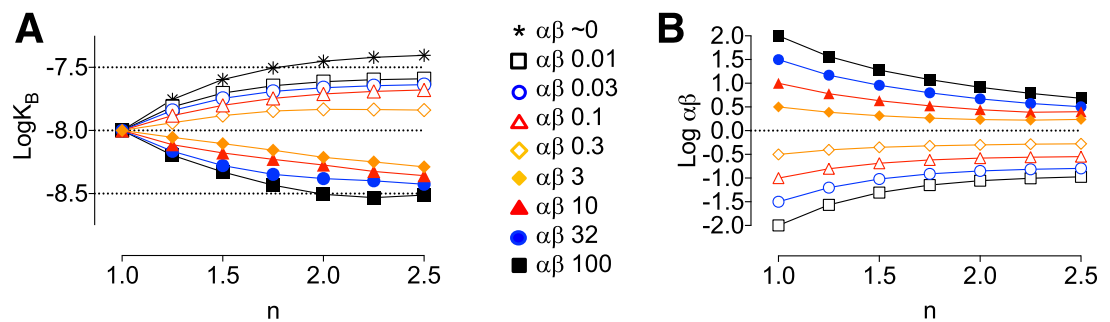

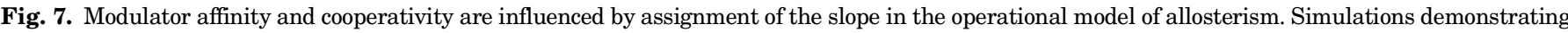

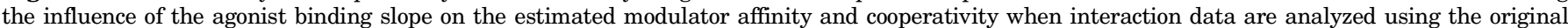

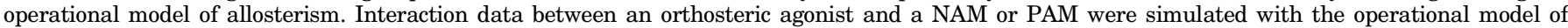

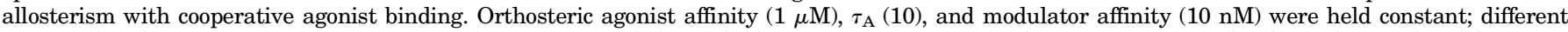

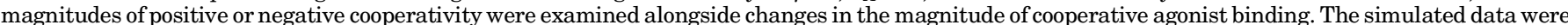
analyzed with the original operational model of allosterism, and $\log K_{\mathrm{B}}(\mathrm{A})$ or $\log \alpha \beta(\mathrm{B})$ estimates were plotted against the agonist binding slope. 
cooperativity can predict likely clinical efficacy or adverse effect liability. Inaccurate estimation of allosteric modulator affinity or cooperativity due to a failure to consider cooperative agonist binding likely also impacts interpretation of structurefunction studies. If cooperativity values are narrowed, then more subtle effects of mutations on modulator cooperativity may have been missed.

In conclusion, we have validated a method for quantifying agonist and allosteric modulator actions at receptors possessing multiple agonist binding sites that interact in a cooperative manner. Our operational models of agonism and allosterism with cooperative agonist binding more accurately quantify the actions of both orthosteric and allosteric drugs acting at GPCRs with cooperative agonist binding and may be used for future drug discovery efforts at these important receptors.

\section{Appendix}

\section{Cooperative agonist operational model}

A model of signal transduction by a receptor with $n B$ binding sites is displayed in the equilibrium:

$$
\begin{aligned}
& (n B) A+R \stackrel{K_{A 1}}{\Leftrightarrow} A R+(n B-1) A \stackrel{K_{A 2}}{\Leftrightarrow} A_{2} R \\
& \quad+(n B-2) A \stackrel{K_{A 3}}{\Leftrightarrow} A_{3} R+(n B-3) A \Leftrightarrow \ldots \Leftrightarrow A_{n B} R \stackrel{K_{E}}{\rightarrow} E
\end{aligned}
$$

Where $K_{E}$ is the value of $A_{n B} R$ that elicits half the maximal system effect and agonist affinity for each site can be described by the equilibrium dissociation constants:

$$
K_{A 1}=\frac{[A][R]}{[A R]}, K_{A 2}=\frac{[A][A R]}{\left[A_{2} R\right]}, K_{A 3}=\frac{[A]\left[A_{2} R\right]}{\left[A_{3} R\right]}, \text { etc }
$$

We see that $K_{A 1} \times K_{A 2} \times K_{A 3} \times \ldots \times K_{A n B}=\frac{[A]^{n B}[R]}{\left[A_{n B} R\right]}=K_{A}{ }^{n B}$, where $K_{A}$ is the geometric mean of the individual equilibrium dissociation constants.

For simplicity, the receptor is considered either empty $(\mathrm{R})$ or fully occupied $\left(\mathrm{A}_{\mathrm{nB}} \mathrm{R}\right):(n B) A+R \stackrel{K_{A}{ }^{n B}}{\Leftrightarrow} A_{n B} R \stackrel{K_{E}}{\rightarrow} E$

$$
K_{A}^{n B}=\frac{[A]^{n B}[R]}{\left[A_{n B} R\right]}
$$

The total receptor concentration can be expressed as:

$$
\left[R_{0}\right]=[R]+\left[A_{n B} R\right]
$$

where

$$
[R]=\frac{K_{A}{ }^{n B}\left[A_{n B} R\right]}{[A]^{n B}}
$$

therefore

$$
\begin{aligned}
& {\left[R_{0}\right]=\frac{K_{A}^{n B}\left[A_{n B} R\right]}{[A]^{n B}}+\left[A_{n B} R\right]} \\
& {\left[R_{0}\right]=\left[A_{n B} R\right]\left(\frac{K_{A}^{n B}}{[A]^{n B}}+1\right)} \\
& {\left[R_{0}\right]=\left[A_{n B} R\right]\left(\frac{K_{A}^{n B}+[A]^{n B}}{[A]^{n B}}\right)}
\end{aligned}
$$

Receptor occupancy is thus denoted:

$$
\left[A_{n B} R\right]=\frac{\left[R_{0}\right][A]^{n B}}{K_{A}^{n B}+[A]^{n B}}
$$

In accordance with the scheme of the operational model of agonism, the logistic function for the transduction of occupancy into response is: $E=\frac{E_{m}\left[A_{n B} R\right]^{n T}}{K_{E}{ }^{n \mathrm{~T}}+\left[A_{n B} R\right]^{n T}}$ where $n T$ is a logistic slope factor describing the transduction of agonist binding into a response (the transducer slope).

Using the previous expression of $\left[A_{n B} R\right]$ gives:

$$
E=\frac{E_{m}\left(\frac{\left[R_{0}\right][A]^{n B}}{K_{A}{ }^{n B}+[A]^{n B}}\right)^{n T}}{K_{E}^{n T}+\left(\frac{\left[R_{0}\right][A]^{n B}}{K_{A}{ }^{n B}+[A]^{n B}}\right)^{n T}}
$$

Multiplying numerator and denominator by $\left(K_{A}{ }^{n B}+[A]^{n B}\right)^{n T}$ gives:

$$
E=\frac{E_{m}\left[R_{0}\right]^{n T}[A]^{n B n T}}{K_{E}^{n T}\left(K_{A}^{n B}+[A]^{n B}\right)^{n T}+\left[R_{0}\right]^{n T}[A]^{n B n T}}
$$

Dividing through by $K_{E}$ and redefining $\frac{\left[R_{0}\right]}{K_{E}}$ as $\tau_{\mathrm{A}}$ gives an operational model of agonism for a receptor with $\mathrm{nB}$ binding sites (Eq 2 in the main text):

$$
E=\frac{E_{m} \tau_{A}^{n T}[A]^{n B n T}}{\left(K_{A}{ }^{n B}+[A]^{n B}\right)^{n T}+\tau_{A}{ }^{n T}[A]^{n B n T}}
$$

For use in Graphpad Prism or similar software, the above equation is described by the following notations, where $n_{\mathrm{T}}$ or $n_{\mathrm{B}}$ will likely need to be fixed to a known or theoretical value to fit real experimental data to this equation, and where a "Basal" response parameter is introduced to accommodate ligandindependent effects that deviate from zero:

$$
\begin{aligned}
& \mathrm{KA}=10^{\wedge} \operatorname{LogKA} \\
& \mathrm{A}=10^{\wedge} \mathrm{X} \\
& \text { tau }=10^{\wedge} \text { Logtau } \\
& \text { Part1 }=(\text { Em }- \text { Basal })^{*} \operatorname{tau}^{*}\left(\mathrm{~A}^{\wedge} \mathrm{nB}\right) \\
& \text { Part2 }=\operatorname{tau}^{*}\left(\mathrm{~A}^{\wedge} \mathrm{nB}\right)+\left(\mathrm{A}^{\wedge} \mathrm{nB}\right)+\left(\mathrm{KA}^{\wedge} \mathrm{nB}\right) \\
& \mathrm{Y}=\text { Basal }+\left(\operatorname{Part1}^{\wedge} \mathrm{nT}\right) /\left(\operatorname{Part}^{\wedge}{ }^{\wedge} \mathrm{T}\right)
\end{aligned}
$$

\section{Operational model of allosterism with cooperative agonist binding}

In a ternary complex consisting of a receptor (lacking constitutive activity), an orthosteric agonist that binds $\mathrm{nB}$ binding sites, and an allosteric modulator, the stimulusgenerating species are $A_{n B} R, B R$ and $A_{n B} R B$. A model of ligand-receptor interactions in this ternary complex is displayed in the equilibrium:

$$
\begin{gathered}
(n B) A+R \stackrel{K_{\stackrel{n}{n} B}}{\Leftrightarrow} A_{n B} R ; \quad B+R \stackrel{K_{B}}{\Leftrightarrow} B R \text { and } \\
A_{n B} R+B \stackrel{\frac{K_{B}}{\alpha}}{\Leftrightarrow} A_{n B} R B
\end{gathered}
$$

Where $K_{A}^{n B}=\frac{[A]^{n B}[R]}{\left[A_{n B} R\right]}, K_{B}=\frac{[B][R]}{[B R]}$, and $\frac{K_{B}}{\alpha}=\frac{\left[A_{n B} R\right][B]}{\left[A_{n B} R B\right]}$ 
From the latter expression we obtain:

$$
\alpha=\frac{K_{B}\left[A_{n B} R B\right]}{\left[A_{n B} R\right][B]}
$$

where

Assuming the pharmacological effect $(E)$ is a function of the total stimulus $\left(S_{T}\right)$ arising from the sum of the stimuli generated from each individual ligand-bound receptor species, then:

$$
S_{T}=S_{A_{n B} R}+S_{B R}+S_{A_{n B} R B}
$$

It is further assumed that the stimulus $(S)$ generated from each individual ligand-bound receptor species is proportional to the product of the intrinsic efficacy of the ligand $(\varepsilon)$ and the concentration of the ligand-bound receptor species, thus:

$$
\begin{aligned}
S_{A_{n B} R} & =\varepsilon_{A_{n B}}\left[A_{n B} R\right] ; S_{R B}=\varepsilon_{B}[B R] ; S_{A_{n B} R B}=\varepsilon_{A_{n B} B}\left[A_{n B} R B\right] ; \text { and } \\
\varepsilon_{A_{n B} B} & =\beta \varepsilon_{A_{n B}}
\end{aligned}
$$

where $\varepsilon_{A_{n B}}$ denotes the intrinsic efficacy of the orthosteric agonist, $\varepsilon_{\mathrm{B}}$ denotes the intrinsic efficacy of the allosteric modulator, and $\beta$ is a coupling factor that describes the effect of the allosteric modulator on the intrinsic efficacy of the orthosteric agonist when the two ligands are bound to the same receptor.

Thus, the effect $(E)$ of an agonist in the presence of an allosteric modulator is processed through the following logistic equation

$$
E=\frac{E_{m} S_{T}^{n T}}{K_{S}{ }^{n T}+S_{T}^{n T}}
$$

where $E_{\mathrm{m}}$ denotes the maximum possible response, $K_{\mathrm{S}}$ denotes a constant that governs the efficiency of stimulus-response coupling and $\mathrm{nT}$ denotes a logistic slope factor (the transducer slope).

If we consider the total receptor concentration:

$$
\left[R_{0}\right]=[R]+\left[A_{n B} R\right]+[B R]+\left[A_{n B} R B\right]
$$

where

$$
\begin{gathered}
{\left[A_{n B} R\right]=\frac{\left[R_{0}\right][A]^{n B}}{[A]^{n B}\left(1+\frac{\alpha[B]}{K_{B}}\right)+K_{A}^{n B}\left(1+\frac{[B]}{K_{B}}\right)}} \\
{[B R]=\frac{\left[R_{0}\right][B]}{[B]\left(1+\frac{\alpha[A]^{n B}}{K_{A}^{n B}}\right)+K_{B}\left(1+\frac{[A]^{n B}}{K_{A}{ }^{n B}}\right)} \text { and }} \\
{\left[A_{n B} R B\right]=\frac{\left[R_{0}\right][A]^{n B}}{[A]^{n B}\left(1+\frac{K_{B}}{\alpha[B]}\right)+K_{A}^{n B}\left(\frac{1}{\alpha}+\frac{K_{B}}{\alpha[B]}\right)}}
\end{gathered}
$$

substituting the above terms into $E=\frac{E_{m} S_{T}{ }^{n T}}{K_{S}{ }^{n T}+S_{T}{ }^{n T}}$ gives the following operational model of allosterism at a receptor with $\mathrm{nB}$ orthosteric agonist binding sites ( $\mathrm{Eq} 4$ in the main text):

$$
\tau_{A}=\frac{\varepsilon_{A_{n B}}\left[R_{0}\right]}{K_{S}}
$$

and

$$
\tau_{B}=\frac{\varepsilon_{B}\left[R_{0}\right]}{K_{S}}
$$

For use in Graphpad Prism or similar software, the above equation is described by the following notations, where $n T$ or $n B$ will likely need to be fixed to a known or theoretical value to fit real experimental data to this equation:

$$
\begin{aligned}
\mathrm{KA} & =10^{\wedge} \operatorname{LogKA} \\
\mathrm{KA} & =10^{\wedge} \operatorname{LogKB} \\
\text { tauA } & =10^{\wedge} \text { LogtauA } \\
\text { tauB } & =10^{\wedge} \text { LogtauB } \\
\mathrm{A} & =\left(10^{\wedge} \mathrm{X}\right) \\
\text { alpha } & =10^{\wedge} \text { Logalpha } \\
\text { betta } & =10^{\wedge} \text { Logbeta } \\
\mathrm{B} & =10^{\wedge} \text { LogAllo }
\end{aligned}
$$

Part1 $=\operatorname{tau} A^{*}\left(\mathrm{~A}^{\wedge} \mathrm{nB}\right) *(\mathrm{~KB}+$ alpha*betta*B $)+\operatorname{tauB} * \mathrm{~B}^{*}\left(\mathrm{KA}^{\wedge} \mathrm{nB}\right)$

$\operatorname{Part2}=\left(\mathrm{A}^{\wedge} \mathrm{nB}\right) * \mathrm{~KB}+\left(\mathrm{KA}^{\wedge} \mathrm{nB}\right) * \mathrm{~KB}+\mathrm{B}^{*}\left(\mathrm{KA}^{\wedge} \mathrm{nB}\right)+\operatorname{alpha}\left(\mathrm{A}^{\wedge} \mathrm{nB}\right) * \mathrm{~B}$

$$
\begin{gathered}
\text { Stim }=\text { Part1 } / \text { Part } 2 \\
\mathrm{Y}=\text { Basal }+\left((\text { Em }- \text { Basal }) *\left(\operatorname{Stim}^{\wedge} \mathrm{nT}\right)\right) /\left(\left(\operatorname{Stim}^{\wedge} \mathrm{nT}\right)+\left(\mathbf{1}^{\wedge} \mathrm{nT}\right)\right)
\end{gathered}
$$

For the purposes of the current study, the model has been simplified further to enable analysis of data when the orthosteric agonist is a full agonist. Therefore, equation 4 in the manuscript reduces to:

$$
E=\frac{E_{m}\left(\tau_{A}[A]^{n B}\left(K_{B}+\alpha \beta[B]\right)+\tau_{B}[B] K_{A}^{n B}\right)^{n T}}{K_{A}^{n B n T}\left(K_{B}+[B]\right)^{n T}+\left(\tau_{A}[A]^{n B}\left(K_{B}+\alpha \beta[B]\right)+\tau_{B}[B] K_{A} n B\right)^{n T}}
$$

Dividing through by $\tau_{A}{ }^{n T}$, and defining $\left[E C_{50}\right]=K_{A} / \tau_{A}$ yields the following expression:

$$
E=\frac{E_{m}\left([A]^{n B}\left(K_{B}+\alpha \beta[B]\right)+\tau_{B}[B]\left[E C_{50}\right]^{n B}\right)^{n T}}{\left[E C_{50}\right]^{n B n T}\left(K_{B}+[B]\right)^{n T}+\left([A]^{n B}\left(K_{B}+\alpha \beta[B]\right)+\tau_{B}[B]\left[E C_{50}\right]^{n B}\right)^{n T}}
$$

\section{Authorship Contributions}

Participated in research design: Gregory, Christopoulos, Leach. Conducted experiments: Diao.

Contributed new reagents or analytic tools: Giraldo, Christopoulos. Performed data analysis: Diao, Gregory, Giraldo, Leach.

$$
E=\frac{E_{m}\left(\tau_{A}[A]^{n B}\left(K_{B}+\alpha \beta[B]\right)+\tau_{B}[B]\left[K_{A}\right]^{n B}\right)^{n T}}{\left([A]^{n B} K_{B}+K_{A}^{n B} K_{B}+K_{A}^{n B}[B]+\alpha[A]^{n B}[B]\right)^{n T}+\left(\tau_{A}[A]^{n B}\left(K_{B}+\alpha \beta[B]\right)+\tau_{B}[B] K_{A}^{n B}\right)^{n T}}
$$


Wrote or contributed to the writing of the manuscript: Gregory, Giraldo, Christopoulos, Leach.

\section{References}

Abdul-Ridha A, Lane JR, Mistry SN, López L, Sexton PM, Scammells PJ, Christopoulos A, and Canals M (2014) Mechanistic insights into allosteric structurefunction relationships at the $\mathrm{M}_{1}$ muscarinic acetylcholine receptor. J Biol Chem 289:33701-33711.

Aurelio L, Valant C, Flynn BL, Sexton PM, Christopoulos A, and Scammells PJ (2009) Allosteric modulators of the adenosine $\mathrm{A}_{1}$ receptor: synthesis and pharmacological evaluation of 4-substituted 2-amino-3-benzoylthiophenes. $J$ Med Chem 52:4543-4547.

Black JW and Leff P (1983) Operational models of pharmacological agonism. Proc $R$ Soc Lond B Biol Sci 220:141-162.

Black JW, Leff P, Shankley NP, and Wood J (1985) An operational model of pharmacological agonism: the effect of $\mathrm{E} /[\mathrm{A}]$ curve shape on agonist dissociation constant estimation. $\mathrm{Br}$ J Pharmacol 84:561-571.

Brea J, Castro M, Giraldo J, López-Giménez JF, Padín JF, Quintián F, Cadavid MI Vilaró MT, Mengod G, Berg KA, et al. (2009) Evidence for distinct antagonistrevealed functional states of 5-hydroxytryptamine $2 \mathrm{~A}$ receptor homodimers. Mol Pharmacol 75:1380-1391.

Brown EM (1983) Four-parameter model of the sigmoidal relationship between parathyroid hormone release and extracellular calcium concentration in normal and abnormal parathyroid tissue. J Clin Endocrinol Metab 56:572-581.

Christopoulos A (1998) Assessing the distribution of parameters in models of ligandreceptor interaction: to log or not to log. Trends Pharmacol Sci 19:351-357.

Cook AE, Mistry SN, Gregory KJ, Furness SG, Sexton PM, Scammells PJ, Conigrave $\mathrm{AD}$, Christopoulos A, and Leach K (2015) Biased allosteric modulation at the CaS receptor engendered by structurally diverse calcimimetics. $\mathrm{Br} J$ Pharmacol $\mathbf{1 7 2}$ $185-200$.

Davey AE, Leach K, Valant C, Conigrave AD, Sexton PM, and Christopoulos A (2012) Positive and negative allosteric modulators promote biased signaling at the calcium-sensing receptor. Endocrinology 153:1232-1241.

Diepenhorst NA, Leach K, Keller AN, Rueda P, Cook AE, Pierce TL, Nowell C, Pastoureau P, Sabatini M, Summers RJ, et al. (2018) Divergent effects of strontium and calcium-sensing receptor positive allosteric modulators (calcimimetics) on human osteoclast activity. Br J Pharmacol 175:4095-4108.

Ehlert FJ (1988) Estimation of the affinities of allosteric ligands using radioligand binding and pharmacological null methods. Mol Pharmacol 33:187-194.

Geng Y, Mosyak L, Kurinov I, Zuo H, Sturchler E, Cheng TC, Subramanyam P, Brown AP, Brennan SC, Mun HC, et al. (2016) Structural mechanism of ligand activation in human calcium-sensing receptor. eLife 5:e13662.

Giraldo J (2015) Operational models of allosteric modulation: caution is needed. Trends Pharmacol Sci 36:1-2.

Huang Y, Zhou Y, Castiblanco A, Yang W, Brown EM, and Yang JJ (2009) Multiple $\mathrm{Ca}^{2+}$ binding sites in the extracellular domain of the $\mathrm{Ca}^{2+}$-sensing receptor corresponding to cooperative $\mathrm{Ca}^{2+}$ response. Biochemistry 48:388-398.

Keller AN, Kufareva I, Josephs TM, Diao J, Mai VT, Conigrave AD, Christopoulos A, Gregory KJ, and Leach K (2018) Identification of global and ligandspecific calcium sensing receptor activation mechanisms. Mol Pharmacol 93: 619-630.

Kenakin TP (2012) Biased signalling and allosteric machines: new vistas and challenges for drug discovery. $\mathrm{Br}$ J Pharmacol 165:1659-1669.

Leach K, Conigrave AD, Sexton PM, and Christopoulos A (2015) Towards tissuespecific pharmacology: insights from the calcium-sensing receptor as a paradigm for GPCR (patho)physiological bias. Trends Pharmacol Sci 36:215-225.
Leach K, Davey AE, Felder CC, Sexton PM, and Christopoulos A (2011) The role of transmembrane domain 3 in the actions of orthosteric, allosteric, and atypical agonists of the $\mathrm{M}_{4}$ muscarinic acetylcholine receptor. Mol Pharmacol 79:855-865.

Leach K, Gregory KJ, Kufareva I, Khajehali E, Cook AE, Abagyan R, Conigrave AD, Sexton PM, and Christopoulos A (2016) Towards a structural understanding of allosteric drugs at the human calcium-sensing receptor. Cell Res 26:574-592.

Leach K, Loiacono RE, Felder CC, McKinzie DL, Mogg A, Shaw DB, Sexton PM, and Christopoulos A (2010) Molecular mechanisms of action and in vivo validation of an $\mathrm{M}_{4}$ muscarinic acetylcholine receptor allosteric modulator with potential antipsychotic properties. Neuropsychopharmacology 35:855-869.

Leach K, Sexton PM, and Christopoulos A (2007) Allosteric GPCR modulators: taking advantage of permissive receptor pharmacology. Trends Pharmacol Sci 28 $382-389$

May LT, Bridge LJ, Stoddart LA, Briddon SJ, and Hill SJ (2011) Allosteric interactions across native adenosine- $\mathrm{A}_{3}$ receptor homodimers: quantification using single-cell ligand-binding kinetics. FASEB $J$ 25:3465-3476.

Moreno Delgado D, Møller TC, Ster J, Giraldo J, Maurel D, Rovira X, Scholler P, Zwier JM, Perroy J, Durroux T, et al. (2017) Pharmacological evidence for a metabotropic glutamate receptor heterodimer in neuronal cells. eLife 6:e25233.

Mutel V, Ellis GJ, Adam G, Chaboz S, Nilly A, Messer J, Bleuel Z, Metzler V, Malherbe P, Schlaeger EJ, et al. (2000) Characterization of $\left[{ }^{3} \mathrm{H}\right]$ quisqualate binding to recombinant rat metabotropic glutamate 1a and 5 a receptors and to rat and human brain sections. $J$ Neurochem 75:2590-2601.

Sato S, Huang XP, Kroeze WK, and Roth BL (2016) Discovery and characterization of novel GPR39 agonists allosterically modulated by zinc. Mol Pharmacol 90: $726-737$

Sengmany K and Gregory KJ (2016) Metabotropic glutamate receptor subtype 5: molecular pharmacology, allosteric modulation and stimulus bias. Br J Pharmacol 173:3001-3017.

Sengmany K, Hellyer SD, Albold S, Wang T, Conn PJ, May LT, Christopoulos A, Leach K, and Gregory KJ (2019) Kinetic and system bias as drivers of metabotropic glutamate receptor 5 allosteric modulator pharmacology. Neuropharmacology 149: 83-96.

Sengmany K, Singh J, Stewart GD, Conn PJ, Christopoulos A, and Gregory KJ (2017) Biased allosteric agonism and modulation of metabotropic glutamate receptor 5: implications for optimizing preclinical neuroscience drug discovery. Neuropharmacology 115:60-72

Sinkins WG and Wells JW (1993) G protein-linked receptors labeled by [3H]histamine in guinea pig cerebral cortex. II. Mechanistic basis for multiple states of affinity [corrected] [published correction appears in Mol Pharmacol (1993) 44: 1278]. Mol Pharmacol 43:583-594.

Stockton JM, Birdsall NJ, Burgen AS, and Hulme EC (1983) Modification of the binding properties of muscarinic receptors by gallamine. Mol Pharmacol 23:551-557.

Storjohann L, Holst B, and Schwartz TW (2008) Molecular mechanism of $\mathrm{Zn}^{2+}$ agonism in the extracellular domain of GPR39. FEBS Lett 582:2583-2588.

Vivo M, Lin H, and Strange PG (2006) Investigation of cooperativity in the binding of ligands to the $\mathrm{D}_{2}$ dopamine receptor. Mol Pharmacol 69:226-235.

Zhang C, Zhuo Y, Moniz HA, Wang S, Moremen KW, Prestegard JH, Brown EM, and Yang JJ (2014) Direct determination of multiple ligand interactions with the extracellular domain of the calcium-sensing receptor. J Biol Chem 289:33529-33542.

Address correspondence to: Katie Leach, Drug Discovery Biology and Department of Pharmacology, Monash Institute of Pharmaceutical Sciences, Monash University, 399 Royal Parade, Parkville, Melbourne, VIC 3052, Australia. E-mail: katie.leach@monash.edu 